\title{
Vibrational Spectroscopy of Complex Synthetic and Industrial Products
}

\author{
Mario Alberto Gómez and Kee eun Lee \\ McGill University, Department of Materials Engineering \\ Canada
}

\section{Introduction}

Arsenic and its adverse effects on the environment and society impose a serious risk as it can be observed in cases such as India, Bangladesh, Vietnam, Nepal, and Cambodia. These problems can arise from geochemical processes but also man-made activities like mining and processing of minerals (Copper, Gold, Cobalt, Nickel and Uranium) that may further contribute to the risk of environmental disasters. In either case, problems and environmental disasters maybe prevented if a detailed chemical identification and understanding of the arsenic species and their chemical properties such as solubility is understood. The processing of these mineral ores (containing various metals) generates arsenic-containing solid wastes which are disposed in tailings management facilities outside in the environment (Riveros et al., 2001; Dymov et al., 2004; Defreyne et al., 2009; Mayhew et al., 2010; Bruce at al., 2011). Most often the phases that are produced after the process is completed is often a multicomponent in nature and contains a variety of elemental and individual phases (often $\geq 3-10$ phases are expected to be present at the end of the process) produced produced along the chemical process. To complicate the understanding of these phases even more, depending upon the processing conditions, the produced unwanted materials (from an economic and recyclable aspect) may also be of a poorly crystalline nature (nano-scale order) in addition to being multicomponent in nature and as such, simple tasks such as identification and then inferring understanding of its chemical properties (such as arsenic release into the environment) becomes very difficult if not nearly impossible. In general, as a result of their multicomponent nature, and perhaps due to historical relation, the use of lab based XRD has been the main tool to tackle the identification of these phases via the use of peak matching and Rietveld type of phase fitting analysis. Recently, synchrotron based soft and hard X-ray techniques (XANES and EXAFS) have been used in a similar fashion to overcome the poorly crystalline (lack of long range order) and multicomponent barrier of these industrially produced complex samples using similar types of mathematical types of fitting routines (Principal Component Analysis and Target Transformation) which still have limitations in identifying mixtures (>2-3) of similar phases with various coordination numbers/environments for the same probing atom of interest.

The need to develop alternative energy storage devices has become one of the main focuses in North America and around the World as a result of the fact that as the population of the world increases, our oil energy supplies are steadily and quickly decreasing with time. 
Therefore intensive research, publications and funding have been mainly invested in Hydrogen energy, Li-ion types of batteries and Photovoltaic types of energy cells, although geothermal and wind type of alternatives are also being explored, the latter remain the focus for an alternative energy solution. To overcome technological plateaus in the development of technologies for energy (Peter, 2011; Scrosati \& Garche, 2010), a deeper understanding of the processes, interactions and properties of the materials is needed to tailor the material to our benefit. However, in reality, the overall identification of the electrochemical process and physical aspects of the materials is nearly impossible due to their multicomponent and complex nano structure. As a result a number of multiple analysis techniques and methods such as X-ray and electron tomography, diffraction, and spectroscopy's, have been employed to investigate the structural and electronic nature of these types of systems. Yet, the complex nature of the multicomponent systems in devices such as Li-ion batteries or Dye Sensitized Solar Cell (DSSC) Photovoltaic's still push the boundaries of the understanding (much that still remains unknown or in some cases debated) of these systems and the analysis methods/techniques that are employed.

In this chapter, no detailed outline of the vibrational techniques, no instrumentation or theory is discussed in this chapter rather the reader is referenced to the numerous published works in journals and books on these subjects from various publishers (Harris and Bertolucci, 1989; Coates, 1998; Hollas, 2004; Nakamoto, 2009). Rather, this chapter describes three individual case studies in two different research areas: Arsenic species formed during the processing of minerals and the biding interactions in Dye Sensitized Solar Cells. In these sections, a description of the importance of the problem at hand and the use/application of vibrational spectroscopy in correlation with other information from other complementary techniques or studies is reported. From these case studies, the great advantages and most importantly disadvantages/limitations of the use of vibrational spectroscopy arise (in addition to other techniques). This is especially true in the case of muti-component systems such as those found in nature or industrially produced materials for which vibrational spectroscopy and other techniques (even the standard XRD) become limited.

\section{The synthetic and natural $\mathrm{Ca}(\mathrm{II})-\mathrm{Fe}(\mathrm{III})-\mathrm{AsO}_{4}$ (yukonite \& arseniosiderite) system}

\subsection{Introduction}

The hydrothermal $\mathrm{Ca}(\mathrm{II})-\mathrm{Fe}(\mathrm{III})-\mathrm{AsO}_{4}$ system has been actively investigated (Swash, 1996; Becze \& Demopoulos, 2007; Becze et al., 2010) given its relevance to precipitation that occurs in industrial arsenical processing liquors (such as those found in the Uranium industry in Northern Saskatchewan, Canada) upon neutralization with lime (CaO). More recently, the presence of these types of phases has gained interest as a result of their formation as secondary mineral in the mining tailing operations of Gold operations.

Among the various calcium ferric arsenate minerals out there, yukonite and arseniosiderite are the most common ones. Yukonite has been reported to occur most often as fractured, gel-like aggregates of dark brownish color. The chemical composition of this rare mineral has been reported to vary substantially in terms of its $\mathrm{Fe}, \mathrm{Ca}$, As and $\mathrm{H}_{2} \mathrm{O}$ content, as can be observed from previous reports (Tyrrell \& Graham 1913; Jambor, 1966; Dunn, 1982; Swash, 1996; Ross \& Post 1997; Pieckza et al., 1998; Nishikawa et al., 2006; Paktunc et al., 2003, 2004; Becze \& Demopoulos 2007; Walker et al., 2009; Garavelli et al., 2009). X-ray diffraction analysis of this material gives broad reflections typical of a mineral with poorly ordered 
(semi-crystalline) structure (Ross \& Post 1997; Garavelli et al., 2009) while electron diffraction measurements (Nishikawa et al., 2006) suggested single crystal diffraction domains with an orthorhombic or hexagonal symmetry. As K-edge EXAFS measurements (Paktunc et al., 2003, 2004) proposed a local molecular structure of yukonite with As-O, AsFe and As-Ca coordination numbers of 4, 3.24 and 4.17 respectively; but the molecular and structural nature of this phase still remains largely unfamiliar. In terms of environmental arsenic stability, Krause \& Ettel (1989) found 6-7 mg/L As released at pH 6.15 after 197 days; Swash \& Monhemius (1994) found it to give approximately 2-4 mg/L As over the $\mathrm{pH}$ range 5-9 after 7 days, while recently Becze \& Demopoulos (2007) found it to give an arsenic release of $1.16-5.11 \mathrm{mg} / \mathrm{L}$ over a $\mathrm{pH}$ range of 7.5-8.8 after $24 \mathrm{hrs}$ of TCLP-like testing. Extension of these tests (Becze et al., 2010) to longer period of time ( $>450$ days) was carried out both in gypsum-free and gypsum-saturated waters at various $\mathrm{pH}$ conditions where the environmental arsenic release was found to be significantly higher in gypsum-free (8.96 $\mathrm{mg} / \mathrm{L}$ at $\mathrm{pH} \mathrm{7,} 47.8 \mathrm{mg} / \mathrm{L}$ at $\mathrm{pH} 8$, and $6.3 \mathrm{mg} / \mathrm{L}$ at $\mathrm{pH} 9.5)$ tests compared to gypsumsaturated waters $(0.75 \mathrm{mg} / \mathrm{L}$ at $\mathrm{pH} 7,2 \mathrm{mg} / \mathrm{L}$ at $\mathrm{pH} 8$, and $6.3 \mathrm{mg} / \mathrm{L}$ at $\mathrm{pH} 9.5$.

Arseniosiderite is another closely related hydrated calcium ferric arsenate mineral relevant to these studies; it was first reported by Koenig (1889) as Mazapilite from the Jesus Maria Mine in Zacatecas, Mexico but was later shown by Foshag (1937) to be Arseniosiderite by comparison with a specimen from Mapimi in Durango, Mexico. This mineral is commonly found in other regions of the world such as Greece, Namibia, Spain, France, Austria, Germany, England, USA, Bolivia and Australia. Paktunc et al. (2003) reported the occurrence of arseniosiderite $\left(\mathrm{Ca}_{2} \mathrm{Fe}_{3}\left(\mathrm{AsO}_{4}\right)_{3} \mathrm{O}_{2} \cdot 3 \mathrm{H}_{2} \mathrm{O}\right)$ and yukonite $\left(\mathrm{Ca}_{2} \mathrm{Fe}_{3}\left(\mathrm{AsO}_{4}\right)_{4}(\mathrm{OH}) \cdot 12 \mathrm{H}_{2} \mathrm{O}\right)$ in the Ketza River mine tailings produced from the operation of a former gold mine/mill in south central Yukon, Canada while in 2004 the same authors (Paktunc et al., 2004) found its presence in the gold ore from the Ketza River mine location. In a separate, study Fillipi et al. (2004) investigated the arsenic forms in contaminated soil mine tailings and waste dump profiles from the Mokrsko, Roudny and Kasperke Hory gold deposits in the Bohemian Massif found in the Czech Republic. It was reported based on chemical composition (EDX) and XRD analysis that arseniosiderite and pharmocosiderite $\left[\mathrm{KFe}_{4}\left(\mathrm{AsO}_{4}\right)_{4}(\mathrm{OH})_{4} \cdot 6-7 \mathrm{H}_{2} \mathrm{O}\right]$ were the only phases present at the Mokrsko location in soils above the granodiorite bedrock. Later on Filippi et al. (2007) published an extensive report on the mineralogical speciation (via SEM-EDS/WDS, Electron microprobe, XRD and Raman spectroscopy) of the natural soils contaminated by arsenic found in the Mokrsko-west gold deposit (Czech Republic) where pharmacosiderite and arseniosiderite (in addition to Scorodite and jarosite) were identified as products of arsenopyrite (FeAsS) and/or pyrite $\left(\mathrm{FeS}_{2}\right)$ oxidation-weathering.

Several authors have commented on the properties of arseniosiderite (Larsen \& Berman 1934; Chukhrov et al., 1958). Palache et al., (1951) and listed the crystal system of arseniosiderite as hexagonal or tetragonal, based on optical data. Moore \& Ito (1974) reported arseniosiderite to have the following chemical formula $\left[\mathrm{Ca}_{3} \mathrm{Fe}_{4}(\mathrm{OH})_{6}\left(\mathrm{H}_{2} \mathrm{O}\right)_{3}\left(\mathrm{AsO}_{4}\right)_{4}\right]$ and to belong to a monoclinic crystal system [A2/a], eight molecular formula units per unit cell $(\mathrm{Z}=8)$ and to be isostructural with robertsite $\left[\mathrm{Ca}_{3} \mathrm{Mn}_{4}(\mathrm{OH})_{6}\left(\mathrm{H}_{2} \mathrm{O}\right)_{3}\left(\mathrm{PO}_{4}\right)_{4}\right]$ and mitridatite $\left[\mathrm{Ca}_{3} \mathrm{Fe}_{4}(\mathrm{OH})_{6}\left(\mathrm{H}_{2} \mathrm{O}\right)_{3}\left(\mathrm{PO}_{4}\right)_{4}\right]$. However, the precise formula of the mitradatite could not be unambiguously defined without detailed knowledge of its crystal structure. Therefore, Moore and Araki published (Moore \& Araki, 1977a) an extensive crystallographic study on mitridatite (and as an extension on arseniosiderite) where they reported mitridatite $\left(\mathrm{Ca}_{6}\left(\mathrm{H}_{2} \mathrm{O}\right)_{6}\left[\mathrm{Fe}_{9} \mathrm{O}_{6}\left(\mathrm{PO}_{4}\right)_{9}\right] 3 \mathrm{H}_{2} \mathrm{O}\right)$ to possess a monoclinic structure [now with a space group, $\mathrm{Aa}]$ and $\mathrm{Z}=4$. Briefly, mitridatite is built up with compact sheets of $\left[\mathrm{Fe}^{\mathrm{III}}{ }_{9} \mathrm{O}_{6}\left(\mathrm{AsO}_{4}\right)_{9}\right]^{-12}$ 
oriented parallel to the $\{100\}$ plane (at the $x \sim 1 / 4$ and $3 / 4$ crystallographic positions). These sheets are built up from octahedral edge sharing nonamers each defining trigonal rings which fuse at their trigonal corners to the edge midpoints of symmetry equivalent nonamers and are decorated above, below and in the plane by the $\mathrm{PO}_{4}$ tetratehedra. In addition to these octahedral sheets, a thick assembly of $\mathrm{CaO}_{5}\left(\mathrm{H}_{2} \mathrm{O}\right)_{2}$ polyhedra and water molecules occur as open sheets parallel to the $\{100\}$ plane (at the $x \sim 0$ and $1 / 2$ positions). The water molecules in these $\mathrm{CaO}_{5}\left(\mathrm{H}_{2} \mathrm{O}\right)_{2}$ polyhedra define an OW-OW' edge, which is shared by two calcium atoms resulting in the formation of $\mathrm{Ca}_{2} \mathrm{O}_{10}\left(\mathrm{H}_{2} \mathrm{O}\right)_{2}$ dimers that contribute to the destruction of trigonal symmetry when they are placed on the octahedral sheets. This arrangement leads to the monoclinic cell symmetry of mitradatite. Arseniosiderite is an isotype of mitradatite, where arseniosiderite obtained from isomorphic replacement of $\mathrm{PO}_{4} \leftrightarrow \mathrm{AsO}_{4}$. This replacement results in dilation along the "a" crystallographic direction because of the contribution in this direction by the larger arsenate tetrahedra is not constrained by the relatively rigid octahedra $\infty\left[\mathrm{Fe}_{9} \mathrm{O}_{33}\right]$ sheets. It is also worth noting that same year Moore \& Araki (1977b) published a short synopsis where they stated that mitradatite (and as an extension arseniosiderite) had the same structure as previously mentioned but reported the space group to be A2/a. Finally, it is worth noting that to date no real crystallographic structure on arseniosiderite has ever been fully reported/published as in the case of isostructure mitradatite. Paktunc et al. (2003) reported via As K-edge EXAFS that the coordination number and bond lengths of the As-O and As-Fe units were essentially identical in yukonite and arseniosiderite, and that at the local structural level, the only difference between yukonite and arseniosiderite was the As-Ca coordination number (4.17 and 2.44, respectively). It should be noted that Paktunc et al. (2003) failed to reference any of the extensive work done by Moore \& Ito (1974), and later Moore \& Araki (1977a,1977b) on the structure of mitridatite (and as extension arseniosiderite) but still somehow managed to fit the EXAFS structure of arseniosiderite and came up with a As-Ca coordination number of 2.44. However, Moore \& Araki (1977a) clearly stated that "each Ca unit is coordinated to four phosphate/arsenate oxygens" thus rendering the previous EXAFS results inaccurate. Moreover, in a subsequent publication, the same researchers (Paktunc et al., 2004) reported different As-Ca coordination numbers for the same phase (arseniosiderite), namely 2.44, 3.60 and 5.5, thus creating more uncertainty as to the true molecular identification of arseniosiderite and how it is distinct at the local molecular level to yukonite. The stability of arseniosiderite in terms of arsenic leachability was first investigated by Krause \& Ettel (1989) who found that after 197 days in water, $\sim 6-7 \mathrm{mg} / \mathrm{L}$ As was released into solution at $\mathrm{pH}$ 6.85. Swash \& Monhemius (1994) also tested the arsenic release of arseniosiderite samples for 7 days and found them it to give release $\sim 0.5-0.7 \mathrm{mg} / \mathrm{L}$ As over the $\mathrm{pH}$ range 5-9. No further arsenic stability tests for arseniosiderite exist to date but due to its crystalline nature they should perform similar or better than yukonite under the same conditions.

Since these $\mathrm{Ca}(\mathrm{II})-\mathrm{Fe}(\mathrm{III})-\mathrm{AsO}_{4}$ phases (Yukonite and Arseniosiderite) were some of the most important arsenic phases found to occur in the Gold mining tailing operations around the world \{Yukon territory,(Paktunc et al., 2003, 2004) and Nova Scotia, Canada (Walker et al. ,2005 and 2009)] as well in the Mokrsko-west gold deposits, Czech Republic (Filippi et al., 2004; Filippi et al., 2007; Drahota et al., 2009; Drahota \& Filippi 2009)\} and as a result of the fact that our experimental evidence showed that synthetic $\mathrm{Ca}(\mathrm{II})-\mathrm{Fe}(\mathrm{III})-\mathrm{AsO}_{4}$ produced phases (in particular yukonite) resulted in excellent environmental arsenic retention properties (Becze \& Demopoulos, 2007; Becze et al., 2010) under similar industrial conditions used in the Uranium industry disposal sites such as those found in Northern 
Saskatchewan, Canada. Yet, in spite of all these studies and important relevance in academia as well as industry, the true molecular nature of these $\mathrm{Ca}(\mathrm{II})-\mathrm{Fe}(\mathrm{III})-\mathrm{AsO}_{4}$ phases (yukonite and arseniosiderite) and how these phases were related was still not yet well understood. Therefore, a series of studies was conducted and published in this system via the use of several analytical structural and molecular techniques, of which vibrational spectroscopy was in particular an invaluable tool (Becze \& Demopoulos, 2007; Becze et al., 2010; Gomez et al., 2010a).

\subsection{Results and discussion}

In the beginning of this work, no synthesis method for these $\mathrm{Ca}(\mathrm{II})-\mathrm{Fe}(\mathrm{III})-\mathrm{AsO}_{4}$ phases had yet been developed in the academic or industrial literature, in spite of their great importance, unlike in the case of other industrially relevant arsenic phases (e.g. Scorodite). Some attempts were conducted and reported by P. M. Swash (1996) during his Ph.D. period under the supervision of A. J. Monhemius but no successful results were ever reported or published. These unsuccessful results were largely due to the fact that most of the syntheses conditions investigate by this research group were largely conducted in acidic media but as it is shown in the synthesis procedure developed by Dr. Levente Becze (Becze \& Demopoulos, 2007; Gomez et al., 2010a; Becze et al., 2010), these phases are only stable at higher $\mathrm{pH}$ conditions $(\sim 8)$ and as such their formation also favours these environment. Once a reproducible and stable method of synthesis of these phases was developed we further investigated how the chemical distribution of the $\mathrm{Ca}, \mathrm{Fe}, \mathrm{AsO}_{4}, \mathrm{OH}$ and $\mathrm{H}_{2} \mathrm{O}$ were distributed among each of these $\mathrm{Ca}(\mathrm{II})-\mathrm{Fe}(\mathrm{III})-\mathrm{AsO}_{4}$ phases.

\begin{tabular}{|c|c|c|c|c|}
\hline \multirow{2}{*}{ Sample } & \multicolumn{4}{|c|}{ Chemical Composition (w.t. \%) } \\
\cline { 2 - 5 } & As & Fe & Ca & $\left(\mathrm{H}_{2} \mathrm{O}+\mathrm{OH}\right)$ \\
\hline Synthetic & $21.60 \pm 0.55$ & $26.52 \pm 2.68$ & $8.75 \pm 0.63$ & 14.8 \\
\hline Tagish Lake & $23.08 \pm 0.40$ & $29.12 \pm 0.58$ & $6.90 \pm 0.12$ & 19.9 \\
\hline Romanech Arseniosiderite & $23.86 \pm 1.13$ & $21.73 \pm 1.01$ & $10.35 \pm 0.37$ & 8.4 \\
\hline
\end{tabular}

Table 1. Elemental analysis of several synthetic yukonite, natural yukonite and natural arseniosiderite. (Gomez et al., 2010a)

From our work (Becze \& Demopoulos, 2007; Gomez et al., 2010a; Becze et al., 2010) on the synthetic and the natural specimens of these mineral phases, it was concluded that yukonite could accommodate a wide range of chemical composition (while still retaining the same phase) according to the general formula $\mathrm{Ca}_{2} \mathrm{Fe}_{3-5}\left(\mathrm{AsO}_{4}\right)_{3}(\mathrm{OH})_{4}-10 \mathrm{xH}_{2} \mathrm{O}$ as shown in our studies (Table 1) and previous literature works. Arseniosiderite is very similar in terms of chemical composition to yukonite (Table 1) but as mentioned previously is a distinct mineral phase. Arseniosiderite has been indicated to be more crystalline counter part of yukonite (Garavelli et al., 2009) and generally has slightly more calcium content in both natural and synthetic (Paktunc et al., 2003, 2004; Garavelli et al., 2009; Gomez et al., 2010a) samples then yukonite. More interesting, it was noted that the chemical formula commonly used in the literature (Paktunc et al., 2003, 2004; Fillipi et al., 2004, 2007; Garavelli et al., 2009) $\mathrm{Ca}_{2} \mathrm{Fe}_{3}\left(\mathrm{AsO}_{4}\right)_{3} \mathrm{O}_{2} \cdot 3 \mathrm{H}_{2} \mathrm{O}$ had a peculiar form in that the use of peroxide types of molecular groups were used but also no hydroxyl groups were included in the formulas as in yukonite. Interestingly, most of these works where the formula was written in that fashion had no reference given to the earlier work of Moore and co-workers (Moore \& Ito, 1974; 
Moore \& Araki, 1977) who determined the crystallographic structure of its phosphate isostructure-mitradatite. In both reports, the authors consistently reported that oxo-anions $\left(\mathrm{O}^{2-}\right)$ and/or hydroxyl units $\left(\mathrm{OH}^{-}\right)$existed in the structure but certainty no peroxo anions $\left(\mathrm{O}_{2}\right)^{2-}$. Moreover, even among the crystallographic reported works, the formulae also varied from $\mathrm{Ca}_{3} \mathrm{Fe}_{4}(\mathrm{OH})_{6}\left(\mathrm{H}_{2} \mathrm{O}\right)_{3}(\mathrm{XO} 4)_{4}$ in 1974 to $\mathrm{Ca}_{6}\left(\mathrm{H}_{2} \mathrm{O}\right)_{6}\left[\mathrm{Fe}_{9} \mathrm{O}_{6}\left(\mathrm{XO}_{4}\right)_{9}\right] \cdot 3 \mathrm{H}_{2} \mathrm{O}$ in 1977 and expressed in many alternative ways to describe its crystallographic arrangement but in no case was the use of peroxide expression used to describe its molecular formulae.

Therefore we decided to examine the vibrational structure of arseniosiderite to examine and verify if indeed these groups $\left(\mathrm{O}_{2}, \mathrm{OH}, \mathrm{H}_{2} \mathrm{O}\right)$ were expressed in the molecular structure of this mineral phase. Peroxo or superoxo vibrational bands are known to be strongly Raman active and occur at $825-870 \mathrm{~cm}^{-1}$ or $1131-1580 \mathrm{~cm}^{-1}$ as in phases such as studtite $\left(\mathrm{UO}_{2}\left(\mathrm{O}_{2}\right) \cdot 4 \mathrm{H}_{2} \mathrm{O}\right)$ (Burns \& Hughes, 2003; Bastians et al., 2004). The Raman spectra of arseniosiderite in our work and previous others (Filippi et al., 2007) did not appear to contain peroxo groups and as such it was determined that expressing the formulae as $\mathrm{Ca}_{2} \mathrm{Fe}_{3}\left(\mathrm{AsO}_{4}\right)_{3} \mathrm{O}_{2} \bullet 3 \mathrm{H}_{2} \mathrm{O}$ was incorrect because it gives the wrong impression that peroxo units exist in arseniosiderite structure which is untrue. In addition, the question of whether hydroxyl groups occurred in the structure arose from the previous work reported by Moore and co-worker earlier work (1974) in which in the use of oxo-anions and hydroxyl anion were included in the formulae but in the later work (1977) only the use of oxo-anions was employed. Essentially, they arrived at this option by investigating bond length-bond strength variations by XRD. On the basis of this investigation they concluded that no hydroxyl $\left(\mathrm{OH}^{-}\right)$anions occur in the structure and treated all anions as oxo-anion $\left(\mathrm{O}^{2}-\right)$ because they were all undersaturated (according to Baur's fourth rule $\Delta \mathrm{p}=$ $\mathrm{p}_{\text {donor- }}$ - acceptor ). Thermo Gravimetric Analysis could only show us how much $\mathrm{OH}+\mathrm{H}_{2} \mathrm{O}$ existed in our sample but not could tell us if one or both definitely existed in the structure of this phase; more over previous X-ray crystallographic works had no additional information due to their lack of Hydrogen atom sensitivity (unlike neutron based diffraction).
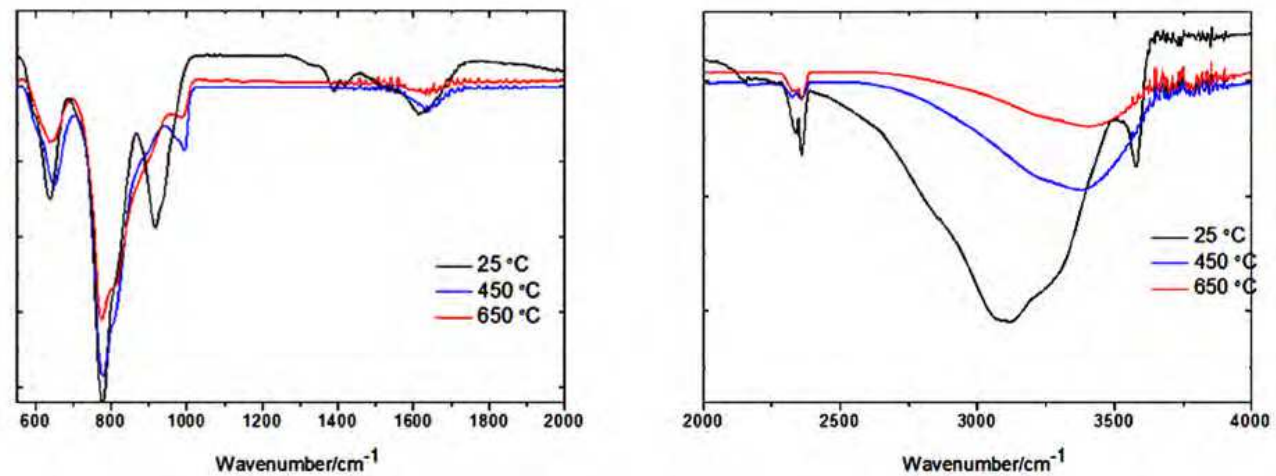

Fig. 1. ATR-IR spectra of arseniosiderite at $25^{\circ} \mathrm{C}, 450{ }^{\circ} \mathrm{C}$ and $650^{\circ} \mathrm{C}$ in the arsenate (left) and hydroxyl (right) stretching regions. (Gomez et al., 2010a)

Thus, in order to clarify this issue, we decided to conduct annealing/heating analysis (450 ${ }^{\circ} \mathrm{C}, 600^{\circ} \mathrm{C}$ and $750{ }^{\circ} \mathrm{C}$ ) of arseniosiderite similarly to that done by Garavelli et al. (2009) but this time using a molecular sensitive technique (ATR-IR) to determine whether there were indeed structural hydroxyl units present. From this analysis as shown above, it was 
confirmed that this structure have water molecules, hydroxyl groups that were found to still exist even after heating the sample to $>600{ }^{\circ} \mathrm{C}$ (Figure 1). Therefore, based on all this vibrational evidence our preference for a "new"(similar to work by Moore \& Ito, 1974) expression formula $\mathrm{Ca}_{3} \mathrm{Fe}_{5}\left(\mathrm{AsO}_{4}\right)_{4}(\mathrm{OH})_{9} 8 \mathrm{H}_{2} \mathrm{O}$ was adopted for this mineral rather than $\mathrm{Ca}_{2} \mathrm{Fe}_{3}\left(\mathrm{AsO}_{4}\right)_{3} \mathrm{O}_{2} \bullet 3 \mathrm{H}_{2} \mathrm{O}$. It should be noted that in the case of yukonite similar heating test were also conducted to verify that indeed both $\mathrm{OH}$ and $\mathrm{H}_{2} \mathrm{O}$ groups are included in the structure, in agreement with previous works (Tyrrell \& Graham, 1913; Jambor 1966; Ross \& Post 1997; Pieczka et al., 1998; Paktunc et al., 2003, 2004; Nishikawa et al., 2006; Becze and Demopoulos 2007; Walker et al., 2009; Garavelli et al., 2009). Finally, in this work it was observed that for arseniosiderite, and additional arsenate IR and Raman active vibrations occurred $\sim 900 \mathrm{~cm}^{-1}$ indicative of protonated arsenate groups. Another such possibility for the existence of additional vibrational bands at such higher wavenumbers is the possibility of more than one type of crystallographic arsenate group which would add extra contributions to the arsenate vibrational region of the spectra. However, this latter possibility is unlikely from inspection of the lack of splitting to the $\mathrm{v}_{3}$ arsenate modes which should be additionally splitted if more than one distinct crystallographic arsenate molecule occurs in the crystal structure (for example in Ferric Arsenate sub-hydrate in section 3.2); more over from the crystallographic data of Moore and co-workers (Moore \& Ito, 1974; Moore \& Araki, 1977a) only one distinct arsenic position is described in its structure. Therefore, the presence of this band in the Raman and IR spectra of arseniosiderite clearly indicates that not only do arsenate groups occur in the structure of this phase but also protonated arsenate groups, something that no previous works on this phase have ever mentioned or notice. Although one brief Raman report was published (Fillipi et al., 2007), the focus of this study was not to investigate the molecular structure of this phase and as such the use of Raman spectroscopy was employed only as a fingerprint tool. However in our case, as a result of the combination of vibrational techniques (IR and Raman) along with a detailed crystallographic knowledge of the structure, new molecular information was obtained.

As can be observed from the brief analysis above (the chemical composition coupled with the vibrational work) it is apparent that a molecular formulae/composition was obtained in both phases (yukonite and arseniosiderite) but their molecular arrangement and local structure was still unknown. This was largely as a result of the fact that although arseniosiderite is a crystalline material, its actual crystal structure has not yet been actually determined (only inferences from its isostructures such as mitradatite have been actually reported).

\begin{tabular}{|c|c|c|c|}
\hline & & Coordination Number & Bond Length $(\AA)$ \\
\hline \multirow{3}{*}{ Arseniosiderite } & As-O & 4.25 & 1.71 \\
\hline & As-Fe & 3.66 & 3.29 \\
\hline & As-Ca & 2.44 & 4.24 \\
\hline \multirow{3}{*}{ Yukonite } & As-O & 4.00 & 1.71 \\
\hline & As-Fe & 3.24 & 3.28 \\
\hline & As-Ca & 4.17 & 4.21 \\
\hline
\end{tabular}

Table 2. Arseniosiderite and Yukonite's first three shell (As-O, As-Fe and As-Ca) coordination numbers and bond lengths based on fitting of As K-edge EXAFS data. (Paktunc et al., 2003, 2004) 
Yukonite is a semi-crystalline unordered type of phase whose structure at the macro or nano level also still remains unknown. From previous literature data (Paktunc et al., 2003, 2004) on As K-edge EXAFS measurements of yukonite and arseniosiderite, the local As-Ca coordination of these two closely related phases which is the only significant difference at the local coordination level to distinguish these two phases arose to question. Moreover, the reports of two distinct As-Ca coordination numbers for arseniosiderite by the same author on subsequent years (Paktunc et al., 2003, 2004) gave rise to even more confusion on this subject (Table 2). Although vibrational spectroscopy can offer us qualitative insight into the coordination of molecules in a crystal structure, most often this occurs as an average of all the molecules. Moreover, its probing range of the structure resembles that of a long range probe due to the size of the wavelength radiation used in these techniques (IR and Raman) and as such, element specific local coordination information is not possible to attain with vibrational spectroscopy. Based on this latter fact and as a result of the contradictory results from previous works (Paktunc et al., 2003, 2004) we decided to conduct our own XAS analysis at the As K-edge and at the Fe and Ca L-edges. From the As K-edge and Fe L-edge X-ray Absorption Spectroscopic analysis (refer to Gomez et al., 2010a) it was determined that in fact the local molecular environment of arsenic and iron of yukonite and arseniosiderite was almost identical (in terms of bond lengths and coordination numbers) to each other, in agreement with that of previous reports.

In complicated systems such as arseniosiderite and yukonite, the Ca L-edge XAS (in particular the XANES region) provides a sensitive probe to determine the local coordination structure at the selected atomic site within $4-5 \mathrm{~A}^{\circ}$ (Borg et al., 1992) from the core atom (in our case Calcium). Therefore it can provide specific information on the local character of the $3 \mathrm{~d}^{0}$ unoccupied states via the $2 \mathrm{p}^{53} \mathrm{~d}^{\mathrm{n}}$ excited electronic state (de Groot et al., 1990; de Groot, 2005). The multi-peaks $\left(a_{1}, a_{2}, b_{1}, b_{2}\right)$ observed in the Ca L-edge XANES spectrum have been attributed to the crystal field arising from the symmetry of the atoms surrounding the $\mathrm{Ca}^{2+}$ ions leading to atomic and charge transfer multiplet effects. These effects have been shown to add extra features and redistribute the intensity over all the lines in the XANES spectrum (Naftel et al., 2001; de Groot, 2005). Moreover, the splitting of these features can be related nonlinearly to the value of the crystal field splitting parameter, coordination and site symmetry around the calcium atoms as well as spin-orbit splitting at the $2 p$ level. Therefore in our studies, the use of the Ca L-edge XAS was employed to determine if in fact the As-Ca coordination was distinct in yukonite and arseniosiderite as previously reported. If indeed the calcium local As-Ca coordination was different in yukonite and arseniosiderite, then the Ca L-edge XANES spectra that should be observed should also be distinct (Naftel et al., 2001; de Groot, 2005; Fleet \& Liu, 2009). As may be seen from the Ca L-edge data (Figure 2), the calcium exhibits the exact same spectra indicating that the same type of calcium coordination and crystal field is observed both yukonite and arseniosiderite. Thus, from the Ca L-edge XANES spectra (Figure 2) it may be inferred that the electronic and local calcium coordination state (As-Ca) and thus coordination number in yukonite is very similar or exactly the same as in arseniosiderite, in contrast to previously reported EXAFS data (Paktunc et al., 2003, 2004). Therefore based on this information and that of previous works on arseniosiderite and yukonite (Moore and Araki, 1977; Paktunc et al., 2003, 2004) it was concluded that "each Ca unit is coordinated to four phosphate/arsenate oxygen's" in both structures (Moore \& Araki, 1977). 


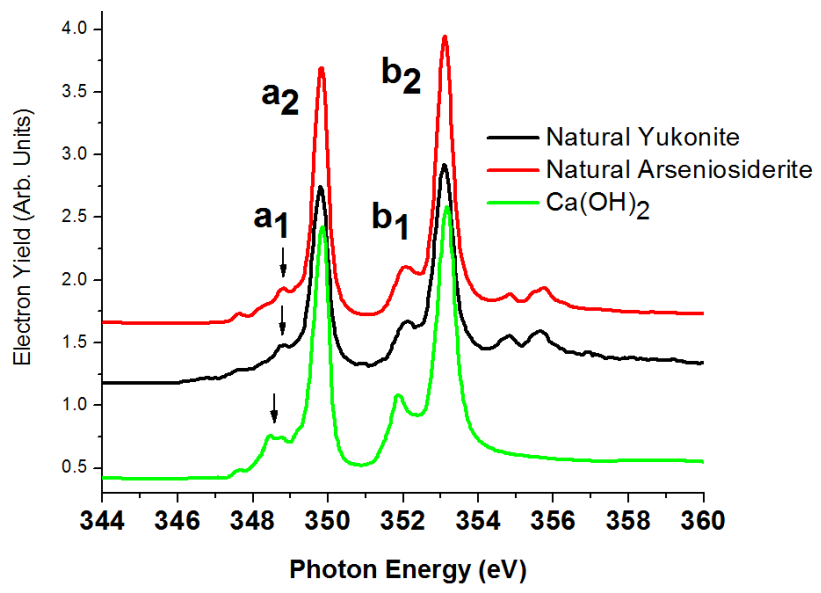

Fig. 2. Ca L-edge XANES of yukonite and arseniosiderite. The spectrum of $\mathrm{Ca}(\mathrm{OH})_{2}$ is also shown for reference as a $\mathrm{Ca}^{+2}$ standard in an octahedral crystal field. (Gomez et al., 2010a)

From these above findings it can be inferred that from a chemical point of view and local coordination structural aspect (XAS results), it was apparent that these structures were only different from the fact that one was a crystalline (arseniosiderite) counter part of the other (yukonite) but aside from this both appeared to be identical in every respect.

SSo, the questioned remained: what exactly makes these two distinct mineral phases not related structurally (aside from crystallinity) or molecularly?

By further investigating the nano structure of these closely related minerals, it was observed that although yukonite was a semi-crystalline composed of glass like micro aggregates, at the nano-scale under the TEM, yukonite was remarkably found to be composed of nanodomained structures which actually showed order at the nanometer level. In case of arseniosiderite, as expected, it was composed of micro ordered domains and showed electron diffraction typical of single crystal domains (Figure 3). Raman spectroscopic measurements indicated that even yukonite's and arseniosiderite's Raman structure of arsenate groups and lattice vibrational modes appeared similar for both phases except for the appearance of the IR and Raman active protonated arsenate bands $\left(\mathrm{HAsO}_{4}\right)$ for arseniosiderite. The Raman vibrational bands were found to be broader in the case of yukonite (synthetic and natural) versus the sharper bands observed for arseniosiderite, confirming that the $\mathrm{AsO}_{4}$ molecules in arseniosiderite were in higher long range order than in yukonite. This of course is in agreement with data and conclusions observed from the XRD and TEM data. Looking at the ATR-IR spectra of these two such closely related phases it was apparent that although their arsenate and $\mathrm{Fe}-\mathrm{OH} / \mathrm{OH}_{2}$ structure was similar in nature, there was an additional feature that only IR spectroscopy allowed us to observe.

The infrared hydroxyl region (3000-4000 $\left.\mathrm{cm}^{-1}\right)$ has the advantage of giving us insights into the intermolecular hydrogen bond nature of minerals (Sumin de Portilla, 1974; Hawthorne, 1976). For example in Scorodite, where two distinct types of intra-molecular hydrogen bonding occurs between the crystal water molecules of metal octahedra and the arsenate groups of the form $\mathrm{MO}-\mathrm{H}---\mathrm{OAs}$; it is possible to relate each specific water $(\mathrm{OH})$ stretching to a particular vibrational band of the two distinct crystallographic water sites (Hawthorne, 1976; Gomez et al., 2010b). The relative strength of H-bonding interactions between the two 



Fig. 3. Transmission Electron Micrograph and Selected Area Diffraction of yukonite (lefttop) and arseniosiderite (right-top). Raman (left-bottom) and ATR-IR (right-bottom) spectra of yukonite and arseniosiderite is also shown below. (Gomez et al., 2010a)

distinct water molecules may be inferred by observing their relative vibrational positions and calculating their H-bond distances using Libowitzky's correlation functions (Libowitsky, 1999). In general, $\mathrm{OH}$ stretches at lower wavenumbers are stronger in bond strength (smaller H-bond bond distances) then those at higher wavenumbers. In the case of arseniosiderite two hydroxyl stretches $(3100,3576 \mathrm{~cm}-1)$ are observed, almost identical to that found in Scorodite (Hawthorne, 1976; Gomez et al., 2010b, 2011b). These two OH stretches in arseniosiderite are indicative of two distinct types of H-bonding environments (one strong and one weak); yukonite on the other hand exhibits only a diffuse band (3111$3215 \mathrm{~cm}^{-1}$ ) indicative of a disordered type of H-bonding, typical of its glassy disordered nature. This latter distinct feature of ordering at the molecular level via H-bonding is a characteristic of each phase; this latter fact gave for the first time, a molecularly based difference between these two closely related phases (yukonite and arseniosiderite) that did not derive from their crystallinity. Based on the Ca $2 p, F e ~ 2 p$ and As-K edge XANES, it is apparent that yukonite exhibited the same local calcium, iron and arsenic local structural environment and units encountered in arseniosiderite but with less long range order in the 
crystal lattice domains (as observed via X-ray and TEM). Therefore, the lower long range order in yukonite is proposed to arise from lack of developed hydrogen bonding environment (observed via ATR-IR) giving rise to poor long range order and is then expressed physically as nano-domain size randomly oriented lattices. In contrast, arseniosiderite displayed a well ordered H-bonding system in its structure giving rise to long range order and a crystalline structure which was physically manifested via microdomain single crystal lattices (TEM). Therefore, based on these results, a molecular and structural link between these two otherwise similar phases (yukonite and arseniosiderite) was proven via the use of vibrational technique coupled with other analysis techniques.

\section{The hydrothermal $\mathrm{Fe}(\mathrm{III})-\mathrm{AsO}_{4}-\mathrm{SO}_{4}$ synthetic system and their relation to industrially produced phases}

\subsection{Introduction}

The ferric arsenate waste solids produced from the hydrometallurgical chemical processing of mineral feedstock's from various metal ores ( $\mathrm{Au}, \mathrm{Co}, \mathrm{Mo}, \mathrm{Zn}, \mathrm{U})$ can be split into two groups depending on their degree of crystallinity (Riveros et al., 2001). At ambient temperature and pressures, poorly crystalline Fe(III)-As(V) solids (Krause \& Ettel, 1989; Langmuir et al., 1999; Jia \& Demopoulos, 2005, 2007) are produced by co-precipitation, which consist of ferric arsenate and arsenate-adsorbed onto ferrihydrite. (Langmuir et al., 1999; Jia \& Demopoulos, 2005, 2007) These co-precipitates are produced from high Fe (III) to $\mathrm{As}(\mathrm{V})$ molar ratio solutions (typically $>3$ ) by lime neutralization (Riveros et al., 2001). Today, this method is still considered to be the most suitable method to treat low arsenic containing process effluent solutions.

In the case of arsenic-rich and iron deficient solutions, crystalline phases such as Scorodite $\left(\mathrm{FeAsO}_{4} \cdot 2 \mathrm{H}_{2} \mathrm{O}\right)$ can be produced. This can be done for example at elevated temperatures, near the boiling point of water $\left(80-95^{\circ} \mathrm{C}\right)$ and under controlled supersaturated conditions. (Singhania et al., 2005; Demopoulos, 2005; Fujita et al., 2008) Crystalline Scorodite is at least 100 times less soluble than its amorphous counterpart (FeAsO4 $\cdot \mathbf{x H 2 O}[\mathrm{am}])$ (Krause and Ettel, 1989; Langmuir et al., 2006; Bluteau \& Demopoulos, 2007) and given its high arsenic content (in comparison to the Fe (III)-As(V) co-precipitates as mentioned above) has been advocated for the fixation of arsenic-rich wastes. (Filippou \& Demopoulos 1997; Fujita et al., 2008) At even higher temperatures $\left(>100^{\circ} \mathrm{C}\right.$, the hydrothermal precipitation range) during autoclave hydrothermal processing of copper (Berezowsky et al., 1999) and gold (Dymov et al., 2004) sulphide feedstock's, other crystalline phases than Scorodite are reported to form some of which exhibit equal or better stability than Scorodite (Swash \& Monhemius, 1994; Dutrizac \& Jambor, 2007, Gomez et al., 2011a).

Swash \& Monhemius (1994) were the first to report on the precipitation and characterization of $\mathrm{Fe}(\mathrm{III})-\mathrm{AsO}_{4}$ compounds from sulfate solutions under industrial like autoclave processing conditions. In their work, four distinct crystalline phases were found to form which were Scorodite, $\mathrm{FeAsO}_{4} \cdot 2 \mathrm{H}_{2} \mathrm{O}$; Basic Ferric Sulfate, $\mathrm{FeOHSO}_{4}$ (BFS); Type1", $\mathrm{Fe}_{2}\left(\mathrm{HAsO}_{4}\right)_{3} \mathrm{zH}_{2} \mathrm{O}$ with $z=4$; and "Type 2", $\mathrm{Fe}_{4}\left(\mathrm{AsO}_{4}\right)_{3}(\mathrm{OH})_{x}(\mathrm{SO} 4)_{\mathrm{y}}$ with $\mathrm{x}+2 \mathrm{y}=3$. The formation of these phases was correlated to two formation variables: temperature and $\mathrm{Fe}(\mathrm{III})$ to $\mathrm{As}(\mathrm{V})$ molar ratio using a fixed retention time. "Type 2 " $(0.34 \mathrm{mg} / \mathrm{L} \mathrm{As})$ was found to meet the TCLP leachability criterion exhibiting similar behavior with Scorodite $(0.8 \mathrm{mg} / \mathrm{L} \mathrm{As})$. A decade later, Dutrizac \& Jambor (2007) published an extensive experimental program involving the precipitation of $\mathrm{Fe}(\mathrm{III})-\mathrm{AsO}_{4}-\mathrm{SO}_{4}$ phases. In their program, the effects of time, initial acidity 
and variable $\mathrm{Fe}(\mathrm{III}), \mathrm{As}(\mathrm{V})$ concentrations were considered. The characterization results via elemental analysis and XRD identified two new phases in addition to Scorodite $\left(\mathrm{FeAsO} \mathrm{A}_{4} \cdot 2 \mathrm{H}_{2} \mathrm{O}\right)$ and basic ferric sulfate (BFS: $\left.\mathrm{FeOHSO}_{4}\right)$. The two new phases, were labeled as "Phase 3, $\mathrm{Fe}\left(\mathrm{AsO}_{4}\right)_{\mathrm{x}}\left(\mathrm{SO}_{4}\right)_{\mathrm{y}}(\mathrm{OH})_{\mathrm{v}}\left(\mathrm{H}_{2} \mathrm{O}\right)_{\mathrm{w}}$ where $\mathrm{x}+\mathrm{y}=1$ and $\mathrm{v}+\mathrm{w}=1$ " and "Phase 4, $\mathrm{FeAsO}_{4} 3 / 4 \mathrm{H}_{2} \mathrm{O}$. Short term $(40 \mathrm{~h})$ leachability tests yielded $0.1 \mathrm{mg} / \mathrm{L}$ As for Phase 3 and 1$3 \mathrm{mg} / \mathrm{L}$ As for Phase 4 indicating that Phase 3 might be an acceptable carrier for the disposal of arsenic. In these studies, the new phases and results were found to be completely different than in the studies of Swash \& Monhemius (1994).

Therefore since the true characteristics, conditions/mechanisms of formation, and long term arsenic environmental stability had not been unequivocally established or determined; a series of synthetic, characterization and environmental arsenic stability tests were conducted and published via the use of several techniques with vibrational spectroscopy being particularly important as will be shown below (Gomez et al., 2010b, 2011a, 2011b).

\subsection{Discussions and results}

The first portion of this work was to synthesize and chemically analyze these $\mathrm{Fe}(\mathrm{III})-\mathrm{AsO}_{4}{ }^{-}$ $\mathrm{SO}_{4}$ phases under the conditions conducted by previous studies (Swash \& Monhemius, 1994; Dutrizac \& Jambor, 2007) but also using our own distinct reacting conditions and reaction variables (Gomez et al., 2011a). From our work and comparison to those previously studied, it became apparent that in spite of the various reaction conditions and variables that each study employed, there was a general agreement in all studies which indicated the formation of similar separate phases from a chemical and structural perspective. However, most of the previous works on this system (Swash and Monhemius, 1994; Dutrizac and Jambor, 2007) have largely based their attention to chemical and structural type of analysis (ICP-OES, XRD, and SEM) and no real consideration of molecular analysis was ever undertaken. This lack of molecular analysis on the previous works part is due to the fact that these bulk-structural types of techniques are the most frequently encountered in these research areas/fields (hydrometallurgical process engineering). It should be pointed out that although one work was published on the IR spectra of some of these phases, little or to no molecular information was ever inferred from the published works available nor any complementary Raman analysis was ever conducted to analyze these types of materials (Swash, 1996; Ugarte \& Monhemius, 1992).

\begin{tabular}{lccccccccc}
\hline \multirow{2}{*}{ Investigation } & \multicolumn{3}{c}{ McGill } & \multicolumn{4}{c}{ \$Swash \& Monhemius } & \multicolumn{3}{c}{ \$Dutrizac \& Jambor } \\
& & & & \multicolumn{3}{c}{ 1994 } & \multicolumn{4}{c}{ 2007 } \\
\hline Weight \% & Fe & As & S & Fe & As & S & Fe & As & S \\
Scorodite & $23-25$ & $28-33$ & $0.2-2$ & $20-24$ & $27-37$ & $\leq 1.3$ & $23-25$ & $28-30$ & $0.9-2.5$ \\
FAsH/Type1/Phase4 & $25-28$ & $32-42$ & $0-0.4$ & $21-23$ & $30-40$ & $<0.33$ & $26-27$ & $36-38$ & $0.2-0.4$ \\
BFAS/Type2/Phase3 & $23-32$ & $14-27$ & $3.2-9$ & $27-38$ & $17-28$ & $\leq 4.3$ & $29-30$ & $13-23$ & $8-13$ \\
\hline
\end{tabular}

\$Note: $\mathrm{AsO}_{4}$ and $\mathrm{SO}_{4}$ values were converted to As and $\mathrm{S}$ values for comparison.

Table 3. Elemental composition of the three main phases of interest found for our work (Gomez et al. 2011a) in comparison to the other previous (Swash \& Monhemius, 1994) and "new" reported phases (Dutrizac \& Jambor, 2007). 

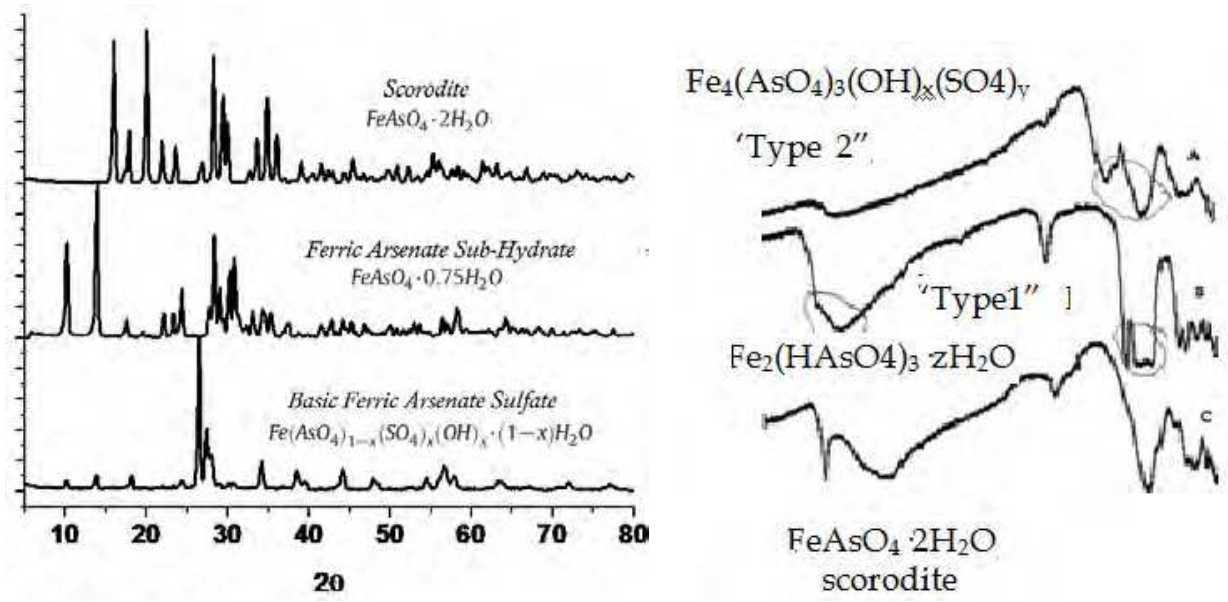

Fig. 4. Powder XRD (left) of the three main phases produced in our studies (Scorodite, Ferric Arsenate sub-Hydrate and Basic Ferric Arsenate Sulfate) (Gomez et al., 2010b, 2011a). The FTIR spectra of scorodite, Type 1 (same as FAsH) and Type 2 (same as BFAS) using transmission collection mode and KBr pellets(Swash, 1996; Ugarte and Monhemius,1992).

This lack of molecular information from previous works (Swash, 1996; Ugarte and Monhemius,1992) was a result of the fact that these previous authors did not bother to investigate which collection mode of Infrared spectroscopy (Transmission, Diffuse Reflectance, Attenuated Total Reflectance or Photo acoustic) would be best to analyze the vibrational structure of these phases and as such they decided to go with the use of the Transmission mode ( $\mathrm{KBr}$ dilution). As can be observed in Figure 4 above, the IR spectra of the phases relevant to these studies lacked the fine structure and resolution necessary to extract any vibrational and molecular information for the various iron arsenate phases produced.

It is noted here that the mode of collection is very important to consider as different samples give rise to better signals for detection in different IR collection modes. In our work (Gomez et al., 2010b, 2011a, 2011b) care was taken to analyze these opaque types of powders in both transmission as well was reflection modes; after careful evaluation of the spectra for each of these phases it was decide that the Attenuated Total Reflectance (ATR) mode would give us enough of an energy range as well as the required spectra resolution to be able to extract useful molecular information of these phases. The ATR mode is especially suited for opaque powders, thin films and solutions, while the transmission mode often tends to 'smear' vibrations due to the less light transmission or detection in opaque solids, (i.e. poorer signal is collected by the detector). Indeed, comparison between the previous IR transmission data (Swash, 1996; Ugarte and Monhemius, 1992) and our work (via ATR) for the same type of phases (Figure 4 and 5) we can clearly see that not only is there more vibrational structure in the regions of interest (arsenate and sulfate $v_{3}$ modes) but we also get the advantage of getting much more additional structure in the hydroxyl region, something that will become important in the molecular analysis of these phases.

Once having the proper vibrational technique to observe as much of the vibrational structure as possible, it was imperative to determine structurally and molecularly if the phases produced in our studies and previous works (Swash \& Monhemius, 1994; Dutrizac \& 

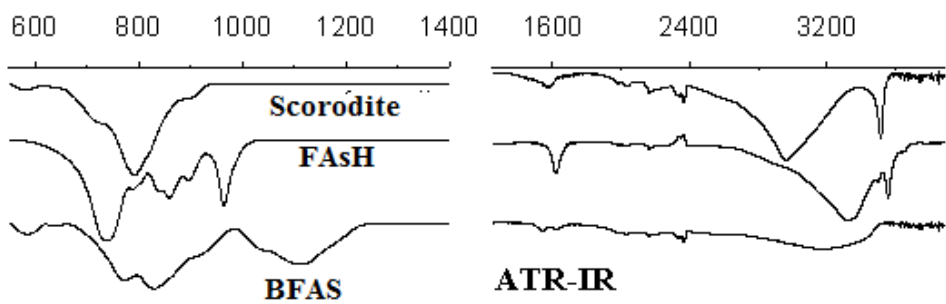

ATR-IR

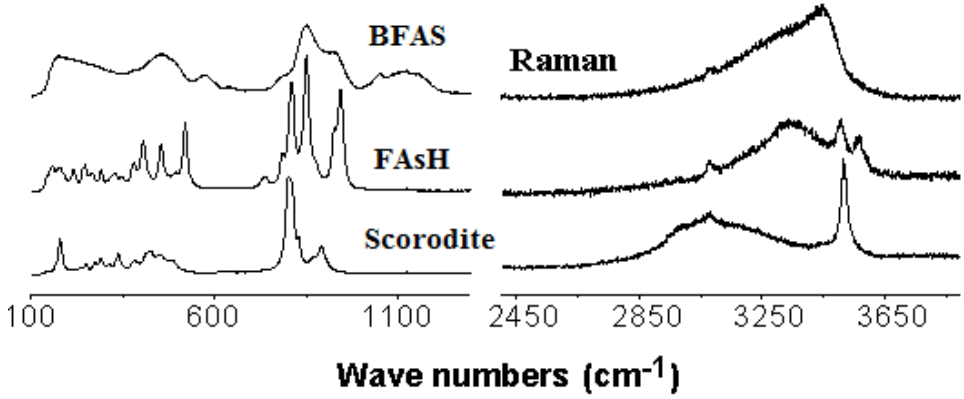

Fig. 5. ATR-IR (top) and Raman of the three main arsenate phases produced in our studies. These were Scorodite, Ferric Arsenate sub-Hydrate and Basic Ferric Arsenate Sulfate. Note the much richer IR structure observed in the arsenate and hydroxyl stretching region for these phases (e.g. Type $1=\mathrm{FAsH}$ ) in comparison to that of the Transmission mode used in Figure 4 above.

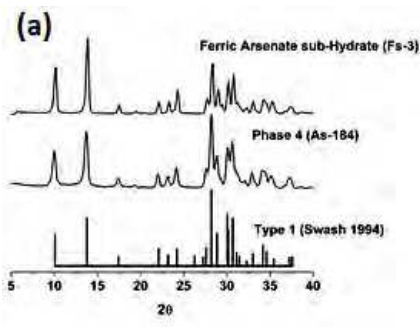

(d)

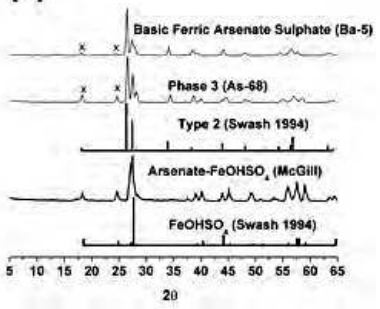

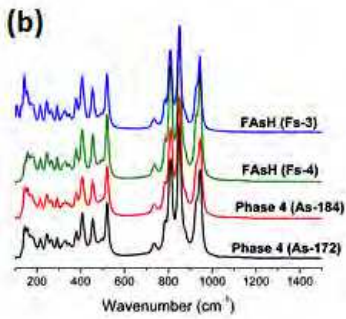

(e)

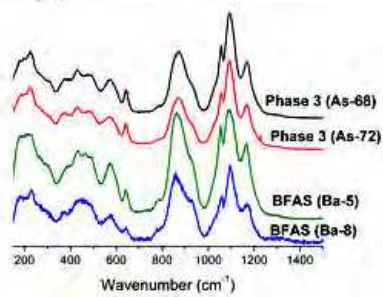

(c)

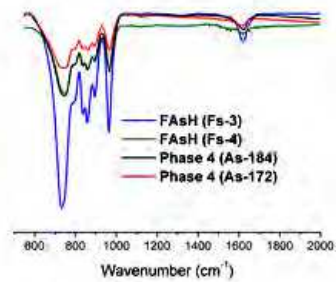

(f)

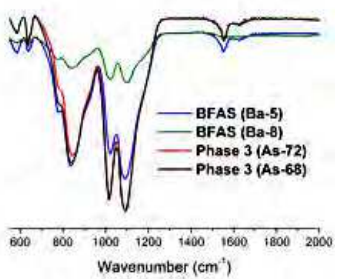

Fig. 6. Powder XRD (left), Raman (middle) and ATR-IR (right) of previous and new reported phases (Type 2, Phase 3, Type 1 and Phase 4) in comparison to the products produced in our studies (Ferric Arsenate Sub-Hydrate and Basic Ferric Arsenate Sulfate). (Gomez et al 2011a) 
Jambor 2007) were all the same, especially in the case of the new claimed phases (Phase 3 and Phase 4) found by Dutrizac and Jambor (2007). From a chemical perspective these phases appeared to be the same in all studies (Table 3) but in the previous published works (Dutrizac \& Jambor, 2007) it was claimed that these phases (namely Phase 3 and Phase 4) were unlike those produced by previous studies (Swash \& Monhemius, 1994; Ugarte \& Monhemius 1992).

As can be seen from the above (Figure 6), it is clear that at the structural level these new claimed phases (Phase 3 and Phase 4) were exactly identical to those produced in our studies (Gomez et al., 2011a) but more importantly those produced in previous studies (Swash \& Monhemius, 1994). Not only was this confirmed at the structural level but more importantly we showed that at the molecular level the arsenate, sulfate and hydroxyl molecules of interest all exhibited the same fingerprint signal but more importantly the same molecular group symmetry exhibited in their crystal structures. Once we identified that all the phases produced under the particular reaction conditions were all the same phase(s), our detailed vibrational and factor group analysis on these phases was conducted (Gomez et al., 2010b).

In the case of Scorodite $\left(\mathrm{FeAsO}_{4} \cdot 2 \mathrm{H}_{2} \mathrm{O}\right)$ our structural and molecular results agreed well with that of the previous studies but the use of vibrational spectroscopy allowed us to spectrocopically observe the molecular incorporation of $\mathrm{SO}_{4} \leftrightarrow \mathrm{AsO}_{4}$ substitution into the Scorodite structure, something which was postulated previosly from elemental analysis but had never been shown in detailed fashion via the use of vibrational spectroscopy until our work (Gomez et al., 2010b, 2011a, 2011b); more over the combination of elemental and molecular analysis allowed us to reformulate the chemical formula of Scorodite in a more appropiate manner as $\mathrm{Fe}\left(\mathrm{AsO}_{4}\right)_{1-0.67 x}\left(\mathrm{SO}_{4}\right)_{x} \cdot 2 \mathrm{H}_{2} \mathrm{O}$.

A similar case occured in the case of the Ferric Arsenate sub-Hydrate $(\mathrm{FAsH})=$ Phase $4=$ Type 1, where it was observed that all these had a similar $\mathrm{Fe}, \mathrm{AsO}_{4}$ and $\mathrm{OH} / \mathrm{H}_{2} \mathrm{O}$ chemical composition, more over the crystal structure as shown via XRD was also the same. However, a contradiction was found yet again in this sytem as the chemical formula proposed for "Type1", $\mathrm{Fe}_{2}\left(\mathrm{HAsO}_{4}\right)_{3} \mathrm{zH}_{2} \mathrm{O}$ by Swash \& Monhemius (1994) was quite distinct from our work in which we proposed $\mathrm{FAsH}$ to be of the form $\mathrm{FeAsO}_{4} \cdot 3 / 4 \mathrm{H}_{2} \mathrm{O}$ based on the crystallographic analysis of this phases using literature data (Jakeman et al., 1991) and XRD simulations with CaRine and Match diffraction software's (Gomez et al., 2011a). Dutrizac and Jambor (2007) indicated that the XRD pattern of their Phase 4 did not match that of any of the ferric arsenate structures in the International Centre for Diffraction Database, but indicated that its crystal structure likely was in the form as that reported by Jakeman et al. (1991) but no XRD simulations were done to verify these results. Therefore to clarify this dilemma of whether this phase actually contained $\mathrm{AsO}_{4}$ or $\mathrm{HAsO}_{4}$ or both in its structure, the use of molecular sensitive techniques such as X-ray Absorption Spectroscopy (NEXAFS and EXAFS) and vibrational spectroscopy (ATR-IR and Raman) was employed.

It has been well documented in the literature that the use of XAS (NEXAFS and EXAFS) can be routinely used to determine and distinguish whether there exist $\mathrm{AsO}_{4}$ or $\mathrm{HAsO}_{4}$ in a structure (Fernandez-Martinez et al., 2008; Guan et al., 2008) as a result of the difference and bond distances they exhibit and their change in symmetry (Myneni et al., 1998). For example, the As-OH bonds are elongated compared to the As-O bonds which is typical for protonated $\mathrm{AsO}_{4}$ tetrahedra (Myneni et al., 1998) and leads to strongly distorted polyhedra. The mean As-O bond lengths in all $\mathrm{AsO}_{4}$ tetrahedra of the three isotypic compounds range from $1.686-1.697 \AA$, which are longer than the average bond length for non-protonated 
tetrahedral (1.682 $⿱$ ) $)$. More over as described in the section above, the XAS spectra is particularly sensitive to changes in coordination state due to its close relation to the crystal field which affects the empty density of states that is expressed in the XAS spectra. Therefore in our case, we expected to have these features be exhibited in the As K-edge NEXAFS or EXAFS data (Figure 7). However upon comparison of a known of Scorodite (which only has $\mathrm{AsO}_{4}$ ) with our FAsH phase, we observed little to no difference in either phase nor any particular contributions from the $\mathrm{HAsO}_{4}$ groups. Therefore, as a result of this a more careful treatment (via the use of factor group analysis) of the vibrational data of the FAsH (and Phase 4) was conducted to determine the types of arsenate groups found in its structure. From the vibrational literature data (Frost et al., 2006; Schwendtner \& Kolitsch, 2007) of compounds that include $\mathrm{AsO}_{4}$ and $\mathrm{HAsO}_{4}$, it is known that protonated arsenate groups, these usually show stretching vibrations at higher wavenumber from 950 to $700 \mathrm{~cm}^{-1}$, while that of unprotonated groups such as Scorodite shows a band $\sim 700-840 \mathrm{~cm}^{-1}$. In the case of $\mathrm{FAsH}=$ Type 1=Phase 4 both the IR and Raman spectra (Gomez et al., 2010b) display a strong band $940-960 \mathrm{~cm}^{-1}$; this band is observed even in the poorly resolved IR data of previous works (Swash, 1996; Ugarte \& Monhemius 1992) who suggested the presence of $\mathrm{HAsO}_{4}$ versus $\mathrm{AsO}_{4}$ groups in this phase. However, as noted previously the crystal structure of this phase was solved before all these studies began (Swash \& Monhemius, 1994 and Dutrizac \& Jambor, 2007) by Jakeman et al. (1991) who indicated that indeed this phase was of a triclinic form with a space group $C_{i}$ and $Z=4$. More importantly, the crystallographic results determined that this phase had two distinct crystallographic arsenate atoms which lie on two different $C_{1}$ crystallographic symmetries; similarly, the $\mathrm{H}_{2} \mathrm{O}$ molecules all occupy $C_{1}$ sites and more importantly there also exist two types of $\mathrm{H}_{2} \mathrm{O}$ molecules in the structure (one covalently bound to the iron octahedra and one electrostatically bound and placed along the channels of the structure). Therefore, with knowledge of the crystallographic arrangement along with the corresponding factor group analysis of the arsenate groups (Gomez et al., 2010b and 2011b) of this phase, it was easy to determine that in fact those vibrations observed at $\sim 940-960 \mathrm{~cm}^{-1}$ were not from protonated arsenate groups but rather were part of the $\mathrm{v}_{3}\left(\mathrm{AsO}_{4}\right)$ stretches and in fact the six vibrations observed in the Raman and IR from $\sim 700-960 \mathrm{~cm}^{-1}$ was actually a combination of the $\mathrm{v}_{3}\left(\mathrm{AsO}_{4}\right)$ and $\mathrm{v}_{1}\left(\mathrm{AsO}_{4}\right)$ coming from the two crystallographically distinct arsenate molecules in the structure (Figure 5). Therefore based on the vibrational analysis and the crystallographic
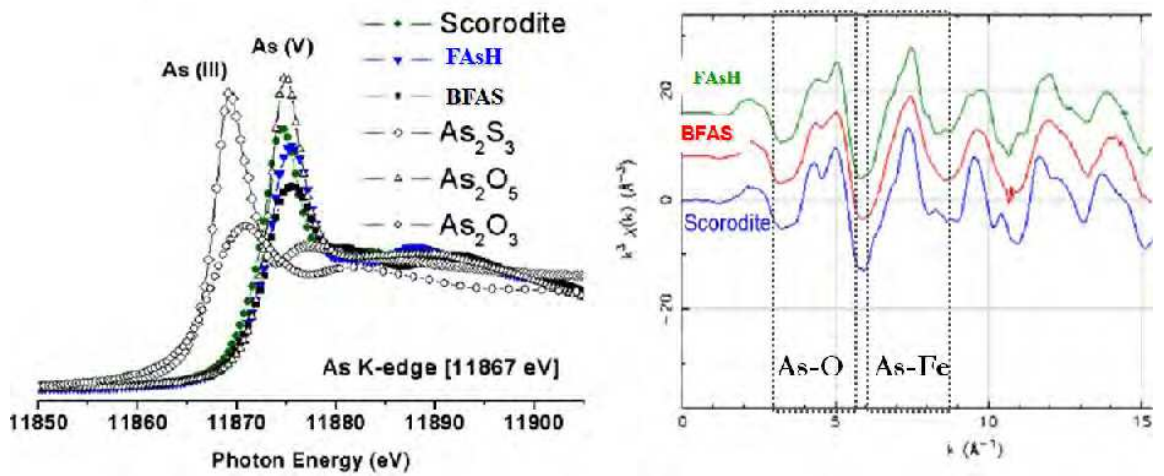

Fig. 7. As K-edge XANES (left) and EXAFS (right) data for Scorodite, Ferric Arsenate subHydrate and Basic Ferric Arsenate Sulfate. 
results from experimental and simulated data (Gomez et al., 2011a), it was determined that in fact the molecular formula for $\mathrm{FAsH}=$ Type $1=$ Phase 4 should not be of the form" $\mathrm{Fe}_{2}\left(\mathrm{HAsO}_{4}\right)_{3} \mathrm{zH}_{2} \mathrm{O}$ " but rather " $\mathrm{FeAsO}_{4} \cdot 3 / 4 \mathrm{H}_{2} \mathrm{O}$ " where the exact amount of water was determined via TGA analysis. Finally, it is interesting to note that in the hydroxyl region of $\mathrm{FAsH}$, there is four distinct vibrations that occur in both the IR and Raman spectra which can be attributed to the two distinct types of water molecules in the crystal structure each which exhibit two distinct types of H-bonding \{as in the case of Scorodite (Gomez et al., 2010b, 2011b)\}.

In the case of Basic Ferric Arsenate Sulfate (BFAS) as mentioned above, no crystal structure existed to date (until recently in our later work; Gomez et al., 2011d) and as a result a detailed group analysis of the vibrational structure could not be conducted (Figure 8). Rather, the use of vibrational spectroscopy was instead used to monitor the $\mathrm{SO}_{4} \leftrightarrow \mathrm{AsO}_{4}$ substitution into the structure and to infer molecular symmetry information for our future crystallographic refinement (Gomez et al., 2011d). In particular it was observed that as the variation of the $\mathrm{SO}_{4} \leftrightarrow \mathrm{AsO}_{4}$ substitution occured in the structure of BFAS, the vibrational structure in the Raman spectra was qualitatively sensitive to the concentration of the groups in the structure but less so to the environment/symetry of the molecules. For example in the case where the sulfate (or arsenate) concentration increased, its Raman band appeared higher in relative intensity. Conversly, the ATR-IR vibrational structure was more sensitive to the environment/symetry of the molecular group of interest and less so to the amount of each group in the structure. In particular, it was observed that the solid solution of $\mathrm{SO}_{4} \leftrightarrow \mathrm{AsO}_{4}$ not only changed the amount of each group incorporated into the BFAS structure but also actually changed the symmetry of the molecular group expressed in the vibrational spectra and more importantly showed us that these groups could occupy the same type of crystallographic sites in the crystal structure, something that would become important later in the determination of its crystal structure(Gomez et al., 2011d).

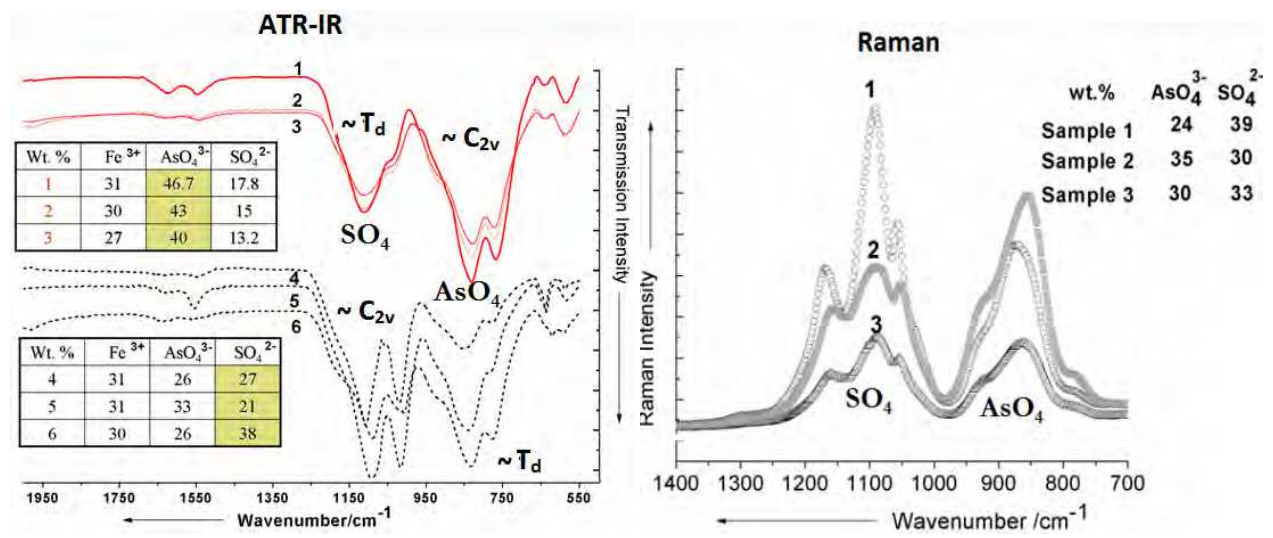

Fig. 8. ATR-IR (left) and Raman (right) spectra of various Basic Ferric Arsenate Sulfate products that contain various amounts of arsenate and sulfate in the solid determined via ICP-AES analysis. (Gomez et al. 2010b)

In terms of industrially produced samples, our work analyzed two industrially manufactured samples from the gold and copper industries (Gomez et al., 2010b, 2011c). In general for industrial practices XRD is the most common form of analysis employed due to 
the fact that is the easiest and most widely available tool with a large enough database for users to simply "click buttons" to get their desired solutions. This approach is often good enough to yield some reasonable results if a priori knowledge of species is assumed based on the matching of chemical elements from elemental analysis; however, this approach fails when the concetration of the phases is below the detection limit of lab based XRD $(\sim 4-5$ w.t.\%) or when the sample is not perfecly crystalline in nature. Indeed in our studies (Gomez et al., 2010b, 2011c) both scenerios were encountered in the industrial samples analyzed (Dymov et al., 2004; Defreyne et al., 2009; Mayhew et al., 2010; Bruce at al., 2011).
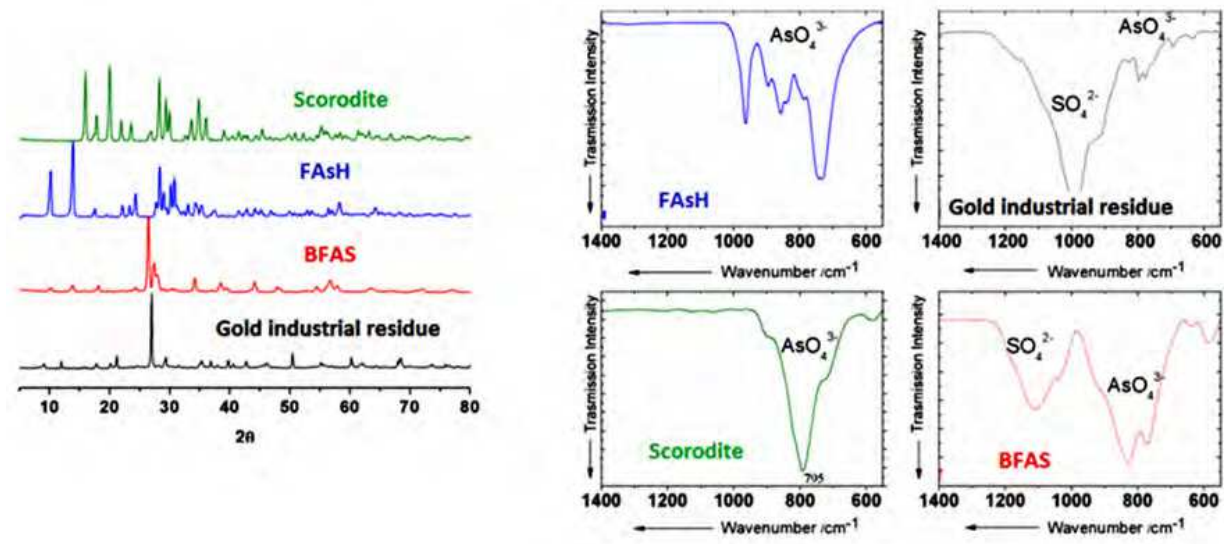

Fig. 9. Powder XRD (left) and ATR-IR (right) of an arsenic containing industrial residue produced from the gold industry compared against relevant synthetic iron-arsenate phases that form under similar conditions. (Gomez et al. 2010b)

For example, in the case of the gold produced residue (Figure 9), although the sample was crystalline in nature, the amount of arsenic $\left(\right.$ as $\left.\mathrm{AsO}_{4}\right)$ in the solid was $\sim 1$ w.t. \% and as a result trying to identify the type of arsenic form produced in the residue was almost impossible with XRD. The use of Raman spectroscopy on this industrial sample gave rise to no Raman active bands by means of four laser wavelengths $(488,514,632$ and $785 \mathrm{~nm})$ and two different spectrometers (bulk and micro). However, upon the use of the ATR-IR technique which can achieve much lower detection limits as well as has the ability to tune to the molecular groups of interest groups of interest while rejecting others if used appropriately (see below); the form of arsenate appeared more clearly as may be seen in the figure above, where in general it only resembled the BFAS type of form and not the other two related ferric arsenate phases.

In the case of the copper produced industrial sample (Figure 10), due to the lower temperatures employed (Bruce at al., 2011) during the copper process $\left(\sim 150{ }^{\circ} \mathrm{C}\right)$, the crystallinity of the industrial sample was found to be much lower in comparison to the gold residue products $\left(\sim 230^{\circ} \mathrm{C}\right)$. Moreover, the arsenic $\left(\mathrm{as}_{\mathrm{AsO}}\right)$ content found in this industrial residue $(\sim 1$ w.t. \%) was again much lower than the detection limits allowed by lab based XRD. Therefore, the lower crystallinity and low content of arsenic in this phase made the positive identification of arsenic phases much less accurate even with Rietveld type of analysis or simple database "click" search matches. As a result, vibrational spectroscopy was employed to investigate the arsenic phase found in this industrial residue. In the case of 

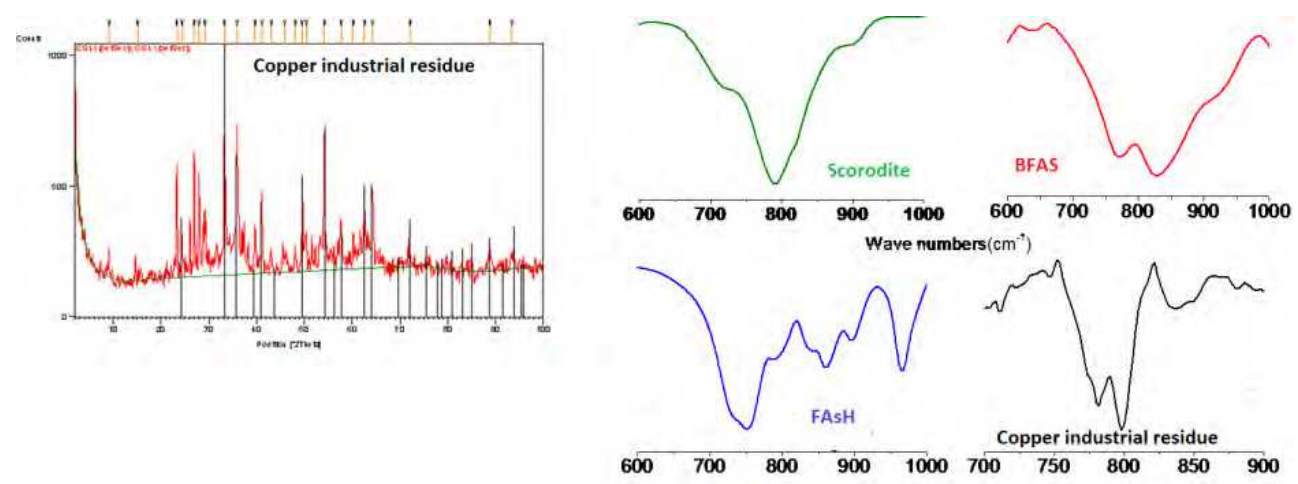

Fig. 10. Powder XRD (left) and ATR-IR (right) of an arsenic containing industrial residue produced from the copper industry. The ATR-IR spectra also shows a comparison of the residue against synthetic iron-arsenate phases which are known to form under similar conditions. (Gomez 2011c)

the Raman spectroscopy (data now show here but refer to Gomez et al., 2011c), vibrational structure was obtained unlike the other case but was found to be largely dominated by the other expected species found in the sample as a result of the chemical process it undergoes (Defreyne et al., 2009; Mayhew et al., 2010; Bruce at al., 2011). For example, it is expected to have both hematite and elemental sulfur as the major constituent of this produced residue; however, upon the analysis of this product with Raman spectroscopy, only hematite could be observed and not in any way elemental sulfur nor any arsenate type of phase. It was only after the elemental sulfur was removed via the chemical method describe in some of our earlier work on other industrial samples (Becze et al., 2009) that the elemental sulfur was extracted and re-crystallized, then Raman spectra was collected to ensure that indeed it was elemental sulfur. Before or after extraction of the elemental sulfur no Raman active arsenate phases were detected. Therefore, the use of ATR-IR spectroscopy was employed again to observe the type of arsenate phase found in the residue, this was done as it offers the advantage of being transparent to the other major species (hematite and elemental) expected to be found in the residue (both which exhibit distinct vibrational signal below $500 \mathrm{~cm}^{-1}$ ) while the distinct arsenate mode for our phases of interest occurred at 700-900 $\mathrm{cm}^{-1}$. It was found by comparison to our other vibrational data that the arsenate species found in the copper industrial residue again resembled that of our BFAS phase.

It is worth for the reader to also note that in our work (Gomez et al., 2010b, 2011a, 2011c) only three phases (and intermixtures of these) could be detected, namely Scorodite, Ferric Arsenate Sub-hydrate/FAsH, Basic Ferric Arsenate Sulfate using the lab based techniques (XRD, ATR-IR, Raman) employed in these studies. Interestingly, Basic Ferric Sulfate $\left.(\mathrm{FeOHSO})_{4}\right)$ was a species detected in previous works formed at high $\left(200-225^{\circ} \mathrm{C}\right)$ and higher $\mathrm{Fe} /$ As ratios $(\sim 4)$ but no clear evidence was obtained from our work using the lab based methods which included vibrational spectroscopy. This was partly as a result of the fact the crystal structure of BFAS had not yet been determined (until recently, Gomez et al., 2011d) and the fact that in order to detect confidently such mixture of species higher resolution synchrotron based XRD and Rietveld refinement was necessary to verify these results, something that previous studies never considered or employed. 


\section{The $\mathrm{TiO}_{2}$ binding mechanism with the $\mathrm{N} 719$ photo-sensitizer for dye- sensitized solar cell applications}

\subsection{Introduction}

As a result of our large demands for energy consumption as our world population increases, the need for alternative energy sources are currently intensively investigated, in particular Dye-sensitized solar cells (DSSCs) have been given major attention due to their application in solar energy conversion and photovoltaic systems (Gratzel, 2001; Kroon et al.,2007; Murakoshi et al., 1995; Falaras, 1998; Finnie et al., 1998; Nazeeruddin et al., 2003; Leon et al., 2006; Kay \& Gratzel, 2002; Shklover et al., 1998; Hagfelt, 2010). In particular, the anatase $\mathrm{TiO}_{2}$ semiconductor/ $\mathrm{Ru}$ complex [cis - (2,2'- bipyridyl - 4,4'- dicarboxylate) ${ }_{2}$ (NCS) ruthenium(II): N719] interface has been studied to understand the sensitization event via the use of spectroscopic [vibrational(Murakoshi et al., 1995; Falaras, 1998; Finnie et al., 1998; Nazeeruddin et al., 2003; Leon et al., 2006; Hagfelt, 2010) and X-ray absorption(Kay \& Gratzel, 2002; Shklover et al., 1998)] and computational studies (De Angelis et al., 2007a, 2007b).

In spite of this research efforts, the binding mechanism (Figure 11) has been debated for decades and remains of importance as it relates to electron transfer and ultimately to the performance of the dye-sensitized photoanode. For example, strong bonding interactions such as covalent bonding (owing to the strong electronic coupling between the semiconductor d-states of $\mathrm{TiO}_{2}$ and the N719 dye molecular orbital) lead to fast electron injection processes and impact the electronic performance of the DSSC (Murakoshi et al., 1995; Wang and Lin, 2010; Bazzan et al., 2011). Moreover, the presence of non (H-bonded) or single (monodentate-ester type) bonds versus two covalent bonds between the $\mathrm{TiO}_{2}$ and N719 molecule are likely to affect the type and amount of electron transfer that occurs during the photo-injection process. For example, two electron bridges in the binding (as bidentate) is likely to favor more electron transfer in the $\mathrm{N} 719-\mathrm{TiO}_{2}$ system versus monodentate type (or electrostatically) type of coordination where only 1 electron bridge occurs (or where no direct link occurs).

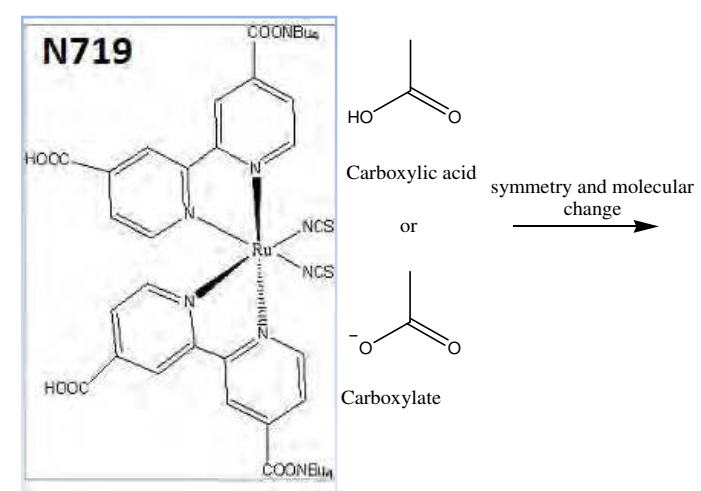

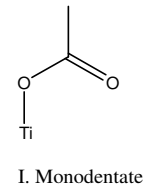

I. Monodentate ester-type

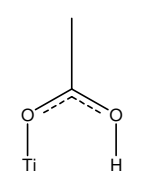

IV. Pseudobridging

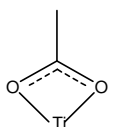

II. Bidentate

chelating

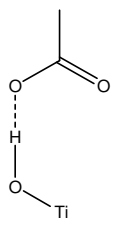

V. Single H-bonded

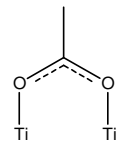

III. Bidentate

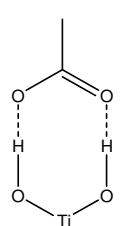

VI. Double H-bonded

Fig. 11. The N719 molecule containing two types of binding ligands (COOH and COO-) and the types of binding mechanism with $\mathrm{TiO}_{2}$ that may occur with these binding groups. (Lee et al. 2010) 
Murakoshi et al. (1995) and Falaras (1998) were the first researchers to report that the N719 photosensitzer bonded to the $\mathrm{TiO}_{2}$ surface via ester-like bond. This was concluded from a shift in the FTIR spectrum for the $\mathrm{v}(\mathrm{C}=\mathrm{O})$ mode which was higher for the N719-adsorbed $\mathrm{TiO}_{2}$ than for that of the pure compound. Finnie et al. (1998) contradicted previous reports (Murakoshi et al., 1995; Falaras, 1998) on the ester-like type of bonding and reported that the N3 molecule (same as N719 but has all acid groups and no carboxylates) complexes to $\mathrm{TiO}_{2}$ in a bidentate chelating or bridging type of mode. In this case, Finnie et al. (1998) used the splitting of carboxylate stretching bands $\left.\left(\Delta v=v_{\text {asym }}\left(C O O^{-}\right)-v_{\text {sym }}\left(C^{-}\right)^{-}\right)\right)$to distinguish possible modes of coordination of carboxylate ion to the $\mathrm{TiO}_{2}$. Shklover et al. (1998) made further suggestions on the anchoring modes of the $\mathrm{N} 3$ sensitizer on the $\mathrm{TiO}_{2}$ based on computational studies where they proposed two thermodynamically favorable models where the N3 molecule was attached via two of its four carboxylic groups coming from two different bipyridine. More specifically, two carboxylic acid groups of N3 were thought to either bind to two adjacent rows of titanium ions through bidentate chelating coordination or interact with surface hydroxyl groups through hydrogen bonds (no supporting experimental evidence was ever presented).

Nazeeruddin et al. (2003) supported Shklover et al. (1998) findings based on their ATR-FTIR spectra where three types of Ru complexes (namely, N3, N712 and N719) were investigated to determine how many carboxylic groups participate in coordination and which groups ( $\mathrm{COOH}$ or $\left.\mathrm{COO}^{-}\right)$are involved in the binding mechanism; the use of all four ligand groups for biding was not feasible from a steric hindrance perspective and therefore two of their four carboxylic groups were proposed to be used in binding. Based on the presence of carboxylate vibrations in the IR spectra of the $\mathrm{N} 719-\mathrm{TiO}_{2}$ surface, they further indicated that two carboxylic groups trans to the NCS group involved in the binding mechanism. The possibility of unidentate coordination was ruled out, because the IR data of the $\mathrm{N} 712-\mathrm{TiO}_{2}$ did not a show the carbonyl band at $\sim 1700 \mathrm{~cm}^{-1}$, confirming the absence of ester type of bond between the $\mathrm{N} 712$ (no $\mathrm{COOH}$ and 4 COO-) and $\mathrm{TiO}_{2}$. Leon et al. (2006) then investigated the $\mathrm{N} 19-\mathrm{TiO}_{2}$ system using SERRS at 514nm, SERS at $632 \mathrm{~nm}$, normal FTIR and ATR-FTIR spectroscopy's. Based on the $\Delta \mathrm{v}$ frequency change of the COO- groups (Deacon and Philip, 1980; Srinivas et al., 2009) they concluded that the $\mathrm{N} 719-\mathrm{TiO}_{2}$ system exhibited carboxylate groups in the bridging or bidentate chelating modes. When the 514 $\mathrm{nm}$ wavelength was used (this energy corresponding to the main absorption band observed in the UV-Vis spectrum "resonance"), the Raman spectra showed the presence of the $\mathrm{v}(\mathrm{C}=\mathrm{O})$ vibration which should not be observed if bidentate chelating occurs and all the carbonyl groups are displaced upon binding. The observation of this band was warranted due to the presence of adsorbed and non-adsorbed molecules which all give a Raman signal at resonance energies ( $~ 514 \mathrm{~nm}$ in the case of the pure N719). The Raman spectra at $632 \mathrm{~nm}$ (SERS but non -resonance) showed that no $\mathrm{v}(\mathrm{C}=\mathrm{O})$ vibration was present, the region of the $\mathrm{v}(\mathrm{C}-\mathrm{O})$ mode was strongly altered, and that the $\mathrm{v}_{\mathrm{sym}}(\mathrm{COO})$ ) vibration appeared; these observations were taken to be a result of the bidentate bonding that occurs upon in adsorption of the N719 which removes all the C=O bands, and only COO- vibrations remain. Recently, Hirose et al. (2008) hypothesized that the N719 dye adsorption on the $\mathrm{TiO}_{2}$ surface was facilitated by the presence of surface $\mathrm{OH}$ sites that leads to the formation of bidentate chelating linkage with one of its four carboxylate groups, but no explanation was offered to why only one ligand group was chosen versus two as in the many previous studies (Finnie et al., 1998; Nazeeruddin et al., 2003; Leon et al., 2006; Kay \& Gratzel, 2002; Shklover et al., 1998; Hagfelt 2010) 
On the basis of the literature works reviewed above, and our own interest in hydroxyl-rich $\mathrm{TiO}_{2}$ as photoanodes in DSSC applications, a greater understanding of the role of the N719 dye's anchoring (COO- and $\mathrm{COOH}$ ) groups and $\mathrm{TiO}_{2}$ 's surface groups (Ti-O, Ti-OH, Ti$\mathrm{OH}_{2}$ ) was needed. To this end, a series of studies was conducted on the interaction of two types of nano-crystalline anatase substrates (commercial one and our own synthetic variety) with the N719 photosensitzer and published via the use of several techniques with vibrational spectroscopy being particularly important as will be shown below (Demopoulos et al., 2009; Lee et al., 2010a, 2011a, 2011b).

\subsection{Discussions and results}

As can be seen from the brief literature review, the binding mechanism of these photosensitzer molecules with anatase $\left(\mathrm{TiO}_{2}\right)$ nano-crystalline substrates have been intensively investigated by numerous research groups fincluding those that pioneered this field (Finnie et al., 1998; Gratzel, 2001; Nazeeruddin et al., 2003; Leon et al., 2006; De Angelis et al., 2007a, 2007b; Hagfelt 2010)\} around the world as a result of the fact that the binding of the dye to the $\mathrm{TiO}_{2}$ substrate plays a key role in the efficiency of DSSC. For example, bidentate type of bonding is preferred over monodentate biding as a result of the fact it simply provides two electron bridges via the use of the covalent bonds.

\begin{tabular}{|c|c|c|c|c|c|}
\hline Compound & $\begin{array}{c}\mathrm{V}_{\text {asym }}\left(\mathrm{COO}^{-}\right) \\
\left(\mathrm{cm}^{-1}\right)\end{array}$ & $\begin{array}{c}v_{\text {sym }}(\mathrm{COO}-) \\
\left(\mathrm{cm}^{-1}\right)\end{array}$ & $\begin{array}{c}\Delta \mathbf{v} \\
\left(\mathbf{c m}^{-1}\right)\end{array}$ & Binding mode & Ref. \\
\hline \begin{tabular}{|c|}
$\mathrm{N} 719$ \\
$\mathrm{~N} 79-\mathrm{TiO}_{2}$ \\
\end{tabular} & $\begin{array}{l}1618 \\
1617\end{array}$ & $\begin{array}{l}1376 \\
1382\end{array}$ & $\begin{array}{l}242 \\
235\end{array}$ & Ester-like unidentate & $\begin{array}{c}\text { Falaras et al. } \\
1998\end{array}$ \\
\hline \begin{tabular}{|c|}
$\mathrm{N} 719$ \\
$\mathrm{~N} 79-\mathrm{TiO}_{2}$ \\
\end{tabular} & $\begin{array}{l}1615 \\
\text { N/A }\end{array}$ & $\begin{array}{l}1371 \\
\text { N/A }\end{array}$ & $\begin{array}{l}251 \\
\text { N/A }\end{array}$ & \begin{tabular}{|c|} 
Bridging/ Bidentate \\
chelating
\end{tabular} & Finnie et al. 1998 \\
\hline \begin{tabular}{|c|}
$\mathrm{N} 719$ \\
$\mathrm{~N} 19-\mathrm{TiO}_{2}$ \\
\end{tabular} & $\begin{array}{l}1608 \\
1602\end{array}$ & $\begin{array}{l}1365 \\
1373\end{array}$ & $\begin{array}{l}243 \\
227\end{array}$ & Bridging & $\begin{array}{l}\text { Nazeeruddin et } \\
\text { al. } 2003\end{array}$ \\
\hline \begin{tabular}{|c|}
$\mathrm{N} 719$ \\
$\mathrm{~N} 719-\mathrm{TiO}_{2}$ \\
\end{tabular} & $\begin{array}{l}1606 \\
1602\end{array}$ & $\begin{array}{l}1354 \\
1375\end{array}$ & $\begin{array}{l}252 \\
227\end{array}$ & \begin{tabular}{|c|} 
Bridging/ Bidentate \\
chelating
\end{tabular} & Leon et al. 2006 \\
\hline \begin{tabular}{|c|}
$\mathrm{N} 719$ \\
$\mathrm{~N} 79-\mathrm{TiO}_{2}$ \\
\end{tabular} & $\begin{array}{l}\text { N/A } \\
1626\end{array}$ & $\begin{array}{l}\text { N/A } \\
1352\end{array}$ & $\begin{array}{l}\text { N/A } \\
274\end{array}$ & Bidentate chelating & Hirose et al. 2008 \\
\hline \begin{tabular}{|c|}
$\mathrm{N} 719$ \\
$\mathrm{~N}^{2} 19-\mathrm{TiO}_{2}$ \\
\end{tabular} & $\begin{array}{l}1603 \\
1607\end{array}$ & $\begin{array}{l}1377 \\
1377\end{array}$ & $\begin{array}{l}235 \\
230 \\
\end{array}$ & Bidentate Bridging & Lee et al. 2010 \\
\hline
\end{tabular}

Table 4 . The $\Delta v$ ( $v$ CoO-asym $-\mathrm{v}$ CoO-sym $)$ values obtained for several studies on the same system and the binding mechanism suggested based on this parameter. (Deacon and Philip, 1980; Srinivas et al., 2009)

From the above review on the previous works, it became evident in almost all cases, the splitting of carboxylate stretching bands $\left(\Delta v=v_{\text {asym }}(C O O-)-v_{\text {sym }}(C O O-)\right)$ was used to distinguish possible modes of coordination of the carboxylate ion to the $\mathrm{TiO}_{2}$. This method was developed by Deacon and Phillip (1980) for known crystallographic carboxylate structures as a result of the low symmetry of $\mathrm{RCO}_{2}^{-}$which makes the differrent types of carboxylate coordination indistinguishable on the basis of the number of infrared or Raman active vibration, and as a result this $\Delta \mathrm{v}$ parameter was invented. This is unlike higher symmetry molecules such as carbonates $\left(\sim D_{3 h}\right)$, sulfates or arsenates $\left(\sim T_{d}\right)$ where a clear removal of degenerate modes can be observed upon the change of symmetry that occurs 
upon bonding of the dye molecule on the substrate. However upon a closer look to the range of $\Delta v$ values for the exact same system in our studies and that of the numerous studies along the years (Table 4), it was realized that there was quite a variation in the range of values and as such this could not be taken as the only evidence of the binding mode in this system. Moreover, it was noted from the literature (Taratula et al., 2006) for other types of molecules with similar binding ligands $(\mathrm{COOH}, \mathrm{COO}-)$, that upon adsorption of the ligands to the $\mathrm{TiO}_{2}$ substrate not only was all the carbonyl band removed $\left(\sim 1700 \mathrm{~cm}^{-1}\right)$ but also the clear formation of the carboxylate bands were also observed $\left(1300,1600 \mathrm{~cm}^{-1}\right)$. To verify such types of results the use of stearic acid was also investigated in parallel (Lee et al., 2010).

Most previous works over the last decades on this system have largely focused only on the dye IR and Raman vibrational structure $\left(1000-2600 \mathrm{~cm}^{-1}\right)$; in our investigations (Demopoulos et al., 2009; Lee et al., 2010, 2011a, 2011b), the use of the higher wavenumber region in the pure photosensitzer dye, pure nano-crystalline anatase substrates and after sensitization was investigated. As will be shown below, the analysis of the higher wavenumber region contributed greatly to the results gathered in this study.
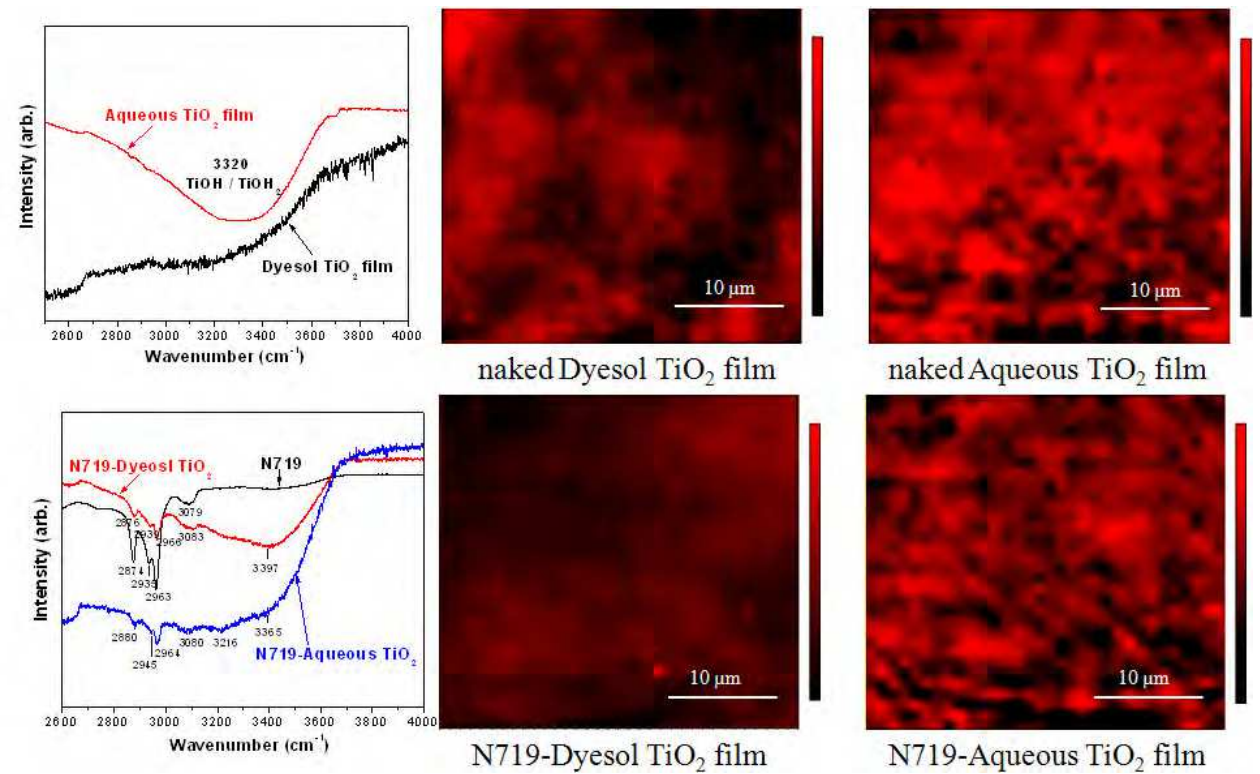

Fig. 12. ATR-IR spectra (Hydroxyl region) and corresponding images of the pure $\mathrm{TiO}_{2}$ substrates (Dyesol and Aqueous) and that of the adsorbed $\mathrm{N719}-\mathrm{TiO}_{2}$ system. (Lee et al. 2010, 2011b)

One of the main aspects of our work (Demopoulos et al., 2009; Lee et al., 2010, 2011a, 2011b) was to compare how two similar nano-crystalline anatase $\mathrm{TiO}_{2}$ substrates (a commercial_Dyesol and our own synthetic Aqueous product) behaved in terms of their bonding properties (via vibrational spectroscopy), distributions (via vibrational imaging) and later from an electronic interaction perspective (Lee et al., 2011b) not only from the photosensitzer (N719_Dye) perspective but also from the substrate point of view. From 
Figure 12 above, it became apparent to us that the synthetic product (Demopoulos et al., 2009) produced under different conditions then the commercial $\mathrm{TiO}_{2}$ substrate (Dyesol) contained a large number of surface $\mathrm{OH} / \mathrm{H}_{2} \mathrm{O}$ groups in comparison to the commercial product. This higher concentration of surface $\mathrm{OH} / \mathrm{H}_{2} \mathrm{O}$ groups was not only observed spectrocopically but was also confirmed visually via the use of ATR-IR imaging (Figure 12), where it was observed that indeed our synthetic aqueous nano-crystalline anatase substrate (Demopoulos et al., 2009) was indeed richer in surface $\mathrm{OH} / \mathrm{H}_{2} \mathrm{O}$ groups in comparison to the commercial products. As mentioned above (Hirose et al., 2008), the presence of certain $\mathrm{OH}$ groups has been shown to be beneficial to the binding of the dye molecule ligands and therefore increase the efficiency of the DSSC; in our case the presence of not only $\mathrm{OH}$ but also $\mathrm{H}_{2} \mathrm{O}$ groups was observed spectrocopically via vibrational spectroscopy, XPS (Lee et al., 2011b) and Thermo Gravimetric Analysis. More interestingly was monitoring how these surface groups $\left(\mathrm{OH} / \mathrm{H}_{2} \mathrm{O}\right)$ behave after the sensitization of the N719 on the two nano-crystalline anatase substrates. From the ATR-IR spectra (Figure 12), we can observe that not all the $\mathrm{OH}$ group vibrations have disappeared from the spectra. This meant that not all the surface groups on the substrates are chemically active to be displaced and bind to the photosensitzer molecule, imaging of the distribution of these surface groups (Figure 12) before and after further confirmed the spectroscopic results. Moreover, we again observed that after (and before) the dye adsorption to our anatase substrate, more surface groups $\left(\mathrm{OH} / \mathrm{H}_{2} \mathrm{O}\right)$ were observed in the synthetic product (Demopoulos et al., 2009) relative to the commercial products, and therefore some of these non bonded surface groups must participate in the binding mechanism of the N719 molecule. These types of analysis and results (Lee et al., 2010, 2011a) had never been conducted or investigated in the previous works over the last decades; as can be observed these results simply arose from taking advantage of the entire IR region (in our case mid-IR) that one analyses which offers various information of several molecular groups in several regions of the spectra and as a result may contain important information to analyze.

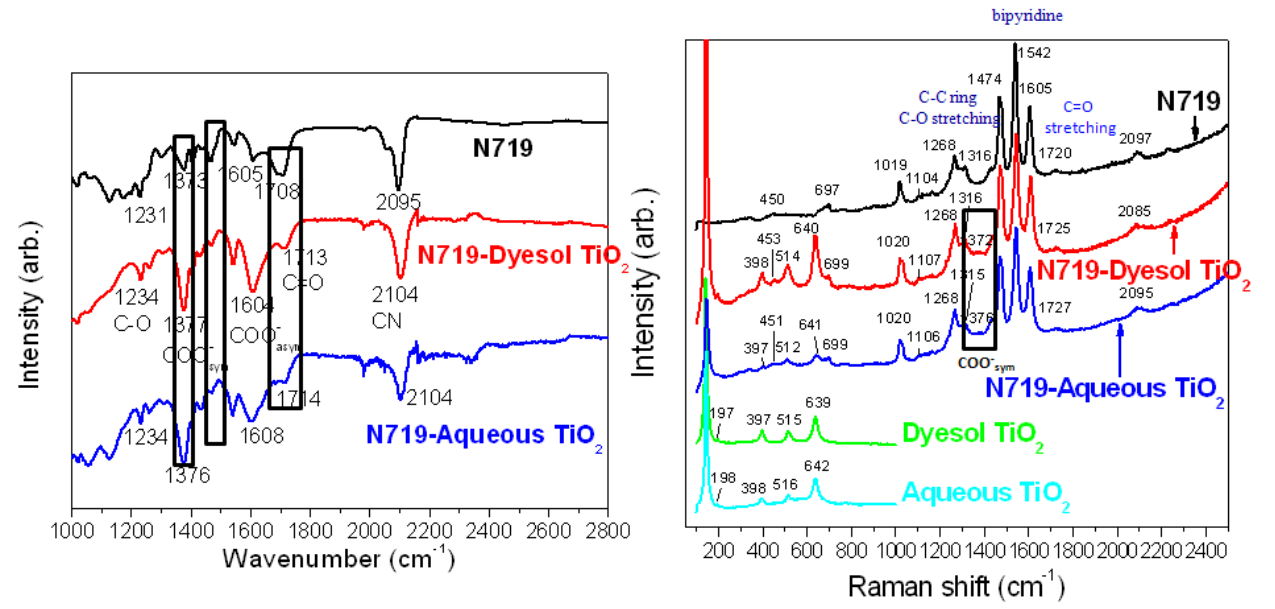

Fig. 13. ATR-IR (left) and Raman (right) spectra of the pure N719 and adsorbed onto both $\mathrm{TiO}_{2}$ substrates [Dyesol and Aqueous]. (Lee et al. 2010)

Thus from the above results, we gathered that the $\Delta v$ parameter had a large range of variation from study to study thus another type of mechanism must have been present in 
the binding mechanism then those previously proposed in literature studies. Moreover, we observed that the presence of surface groups remained after the adsorbtion indicating that not all these surface sites on the anatase substrates are displaced once the adsorbtion occurs. Therefore, we also decided to investigate the dye vibrational region to observe the changes that occur to the vibrational structure of the photosensitizer molecule before and after dye adsorbtion. The first thing that may be observed from the Raman and ATR-IR spectra (Figure 13) is that when we compare the pure dye (N719) spectra with that of the adsorbed states in either substrate (aqueous and Dyesol), little to no difference is observed from one state to the other unlike in other cases for molecules with similar binding ligands (Taratula et al., 2006).

More specifically in the case of the Raman spectra, we observed a carboxylate stretches which may be indicative of binding of some of the ligand molecules ( $\mathrm{COO}^{-}$and/or $\mathrm{COOH}$ ) as stated in previous works but also could simply be from the carboxylate groups not bound to the anatase surface (Figure 13). It should be noted as shown in Figure 11 above, the N719 Molecule has 4 biding ligands from which only two are reported to bind to the anatase substrate, depending whose article is read either both carboxylates or carboxylic acids are thought to be the main groups participating in the binding from an energetic point of view. Either way, two of these are carboxylates and the other two are carboxylic acids. More importantly, the Raman results showed us that there was still $\mathrm{C}=\mathrm{O}$ stretches observed in the spectra after the dyes adsorption on both substrates, this meant that not all the carboxylic acids groups bonded after the adsorption of the dye molecule. This in fact is an interesting fact as previous studies (Leon et al., 2006) have mentioned that the lack of this band meant that the acid groups were all bound to the substrates and stated that if observed at resonance energies (in this case $514 \mathrm{~nm}$ ) that this is a result of getting the signal from all molecules deposited (bonded and non-bonded). To confirm these findings, we decided to probe this same system at non-resonance energies (632 $\mathrm{nm}$ laser probe) but at the same time avoiding emission excitation energies $(\sim 785 \mathrm{~nm})$. From these measurements, we observed that indeed at non resonance energies, the presence of these $\mathrm{C}=\mathrm{O}$ bands was still present and as such this meant that indeed not all the acid groups were displaced upon binding of the dye molecule on the substrate (commercial and synthetic). Moreover, not only were these $\mathrm{C}=\mathrm{O}$ bands presented after adsorption but also were found to be shifted to higher energy relative to the pure N719 dye indicating that these groups likely were under the influence of some type of interactions (such as $\mathrm{H}$-bonding with surface Ti-OH/ $\mathrm{H}_{2} \mathrm{O}$ groups as observed above) upon binding onto the anatase substrates. This latter trend (shift in energy of non bonded groups) was observed was also observed for the NCS groups of the adsorbed states relative to the pure states. In our work (Lee et al., 2010, 2011a), as mentioned above, not only were we interested in the bonding mechanism of this system but also we wanted to investigate how two otherwise similar nano-crystalline anatase substrates behaved in terms of their binding distributions throughout the photoanode. From the Raman spectral information gathered above, the use of Confocal Raman Imaging (Figure 14) was used to tune the energies of the molecular groups of interest and show the spatial distributions of these groups on these substrate before and after dye adsorption, but most importantly to observe how the bonded and non bonded groups were distributed throughout the two anatase (commercial and synthetic) substrates. For example, we decided to observe the bypiridine stretches (which definitely do not participate in bonding) to 
observed how the overall dye was distributed in the substrates, the COO- was used to observe where the dye was covalently bonded to the substrate and the $\mathrm{C}=\mathrm{O}$ band to image how the non bonded groups from the dye molecules were distributed throughout the substrates (dark regions represented where they were bonded and bright regions where unbounded groups were observed). In all cases regardless of what group of interest was imaged, it was observed that the distribution of the dye (and therefore its molecular groups) on our synthetic substrate was unlike that of the commercial Dyesol. For our synthetic substrate, localization of the dye molecules and its bonded and non-bonded groups occurred as hot spot regions throughout the substrate, while in the case of the commercial substrate, the dye and its groups are distributed fairly evenly throughout the substrate. It should be noted to the readers that both the commercial and our synthetic anatase substrates exhibited similar roughness factors in the nanometer scale and as such these changes in distribution observed in the Raman images could not be formed as a result of their surface topography but rather from a chemical property of the materials. Thus in the case of our synthetic substrate, the localization of hot spot for the dye molecules bonding and non bonding groups on the substrate may result from the different surface energetic that occur as a result of the localization of substrate surface groups $\left(\mathrm{Ti}-\mathrm{OH} / \mathrm{Ti}-\mathrm{OH}_{2}\right)$ which is greater in our synthetic substrate (Demopoulos et al., 2009) then the commercial Dyesol one.

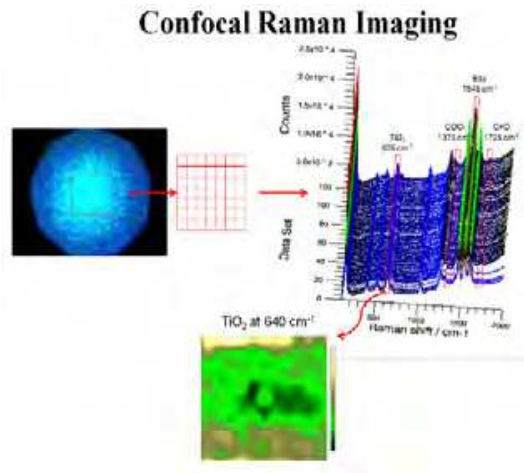

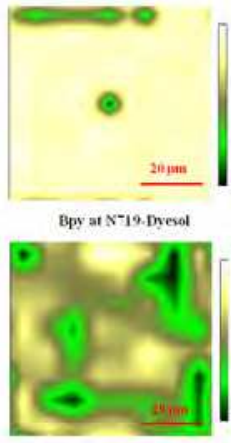

Bpy at N-19 Aqueous

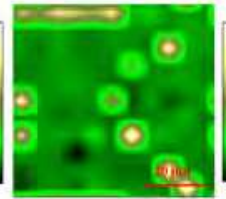

$\mathrm{COO}_{\mathrm{nm}}$ at N-19-Dyesol

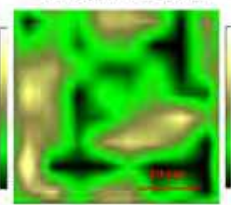

$\mathrm{COO}_{\mathrm{ma}}$ at No19 Aqueous

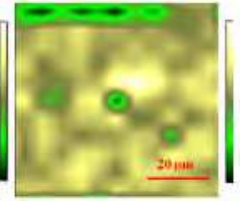

$\mathrm{C} \rightarrow \mathrm{O}$ at $N-12$ - Dyrsel

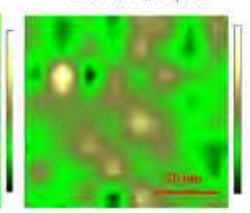

$C \sim 0$ at $N=19$ aqueur

Fig. 14. Raman imaging principle and Raman images of the certain molecules of interest for the N719 molecule adsorbed onto both $\mathrm{TiO}_{2}$ substrates (Dyesol_comercial and Aqueous_our synthetic). (Lee et al. 2010, 2011b)

The ATR-IR data for the dye region before and after the sensitization, similar to the Raman data showed that again from comparison of the pure dye to the adsorbed state, there was little to no change (aside from a small change in intensity) to the $\mathrm{COO}^{-}$and $\mathrm{C}=\mathrm{O}$ bands (Figure 13). As mentioned above, in the case of other molecules such as the bulky m-PyEPE-Ipa (Taratula et al., 2006) or the small stearic acid, upon binding of these molecules with the $\mathrm{TiO}_{2}$ substrates, the vibrational structure of the pure molecules changes completely before and after the adsorption (i.e. the $\mathrm{C}=\mathrm{O}$ band is removed and only COO- bands remain). Not only were these non bonded groups present but also a shift in energy was observed for both $\mathrm{C}=\mathrm{O}$ and NCS groups, in agreement with our Raman data. Therefore, the 
presence of these $\mathrm{C}=\mathrm{O}$ groups indicated again that not all the groups were used up in upon the adsorption of the dye and their shift in energy was a result of their interaction with the non bonded surface Ti-OH/ $\mathrm{H}_{2} \mathrm{O}$ groups on the surface. A similar situation was observed for the $\mathrm{COO}^{-}$groups, were the $\Delta \mathrm{v}$ parameter splitting of these before and after sensitization were indicative of bidentate bridging complexes, in agreement with previous studies but the lack of change to their vibrational structure and their energy shifts of both modes ( $\mathrm{COO}_{- \text {sym and assym }}$ ) was indicative of them interacting with the non bonded surface $\mathrm{Ti}-\mathrm{OH} / \mathrm{Ti}-\mathrm{H}_{2} \mathrm{O}$ groups.

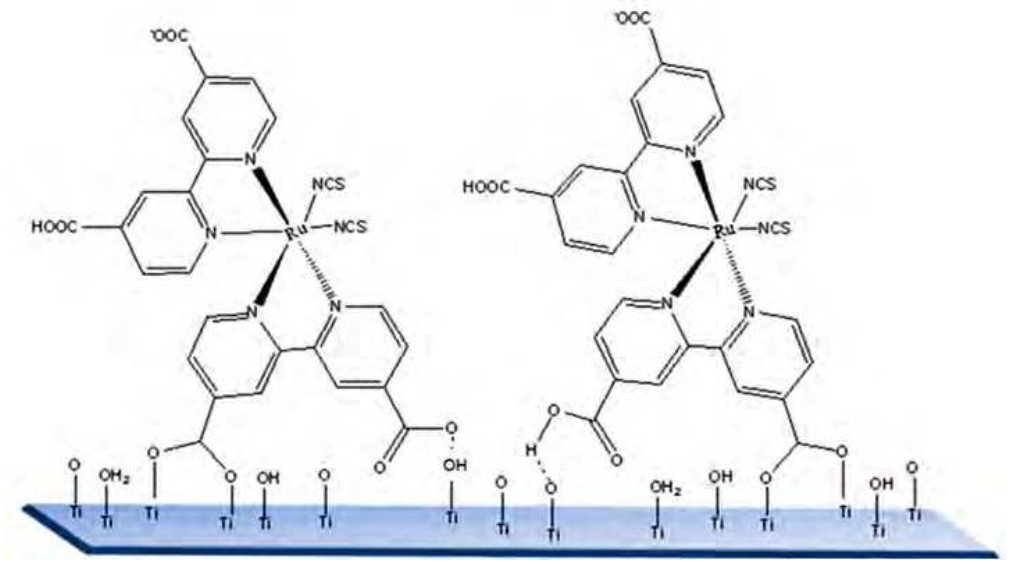

Fig. 15. New Binding mechanism for the N719-TiO system based on our vibrational spectroscopic and imaging data. (Lee et al., 2010)

Therefore, based on the vibrational spectroscopic and imaging data gathered we proposed a new modified structure for the binding mechanism of $\mathrm{N} 719$ dye on $\mathrm{TiO}_{2}$ which has now become the standard accepted model by all the leading experts/pioneers in the field (see citations of Lee et al., 2010). Although Bazzan et al. 2011 recently published an article that stated that "there is as yet no commonly accepted understanding of the biding mechanism", in their published work, they used our proposed concepts and binding mechanism to explain the binding mechanism in their work. In our mechanism (Figure 15), the binding mechanism of the N719 dye onto $\mathrm{TiO}_{2}$ was proposed to occur via two neighboring carboxylic acid/carboxylate groups linked on the same bipyridine ligand via a combination of bidentate-bridging and H-bonding, the latter part was something that had never been considered previously in the extensive research on this system. In our new binding mechanism, the formed surface covalent complex is sterically stabilized via the development of $\mathrm{H}$-bonding between the $\mathrm{TiOH} / \mathrm{Ti}^{-} \mathrm{OH}_{2}(\mathrm{Ti}-\mathrm{O})$ and $\mathrm{COO}-(\mathrm{COOH})$ groups. Moreover, the involvement of only one carboxylic group in the adsorption of N719 via covalent bidentate bridging was adopted here [as in Hirose et al., (2008)] as a result of very recent work by Srinivas et al. (2009) involving the adsorption of sensitizers on $\mathrm{TiO}_{2}$ carrying malonic and cyanoacrylic acid biding groups, who found that the monocarboxylic acid group showed stronger binding affinities as well as slightly higher IPCE and efficiencies than dicarboxylic acid groups, and therefore the requirement for two ligand groups to be covalently bonded versus only one was not necessary to produced higher IPCE and efficiencies. 


\section{Conclusions}

In the first case, the $\mathrm{Ca}$ (II)-Fe(III)- $\mathrm{AsO}_{4}$ phases (yukonite and arseniosiderite), the use of vibrational spectroscopy was employed as a finger printing tool, to correct molecular formulae via detection of certain molecular groups of interest $\left(\mathrm{HAsO}_{4}, \mathrm{H}_{2} \mathrm{O}, \mathrm{OH}\right)$ but most importantly, it gave us an understanding to how these two distinct phases were divergent to each other at the molecular scale and why their crystallinity (long range order) differed. This was something that was previously speculated but no experimental evidence was ever really presented to explain this phenomenon. X-ray Absorption based techniques (XANES and EXAFS) of these phases (yukonite and arseniosiderite) failed to recognize this difference as a result of the fact that it could only probe three types of shells (As-O, As-Fe, As-Ca) from the core excited atom of interest. This limitation arose from the fact that these were the same at the local structural level for these two phases, based on our and previous works. Therefore the use of vibrational analysis and ATR-IR spectroscopy enabled us to reveal that it was the nature of the $\mathrm{H}$-bonding molecular structure in these two phases (yukonite and arseniosiderite) which caused the difference in the physical order (crystallinity) expressed. For the $\mathrm{Fe}(\mathrm{III})-\mathrm{AsO}_{4}-\mathrm{SO}_{4}$ system, as a result of the fact that much work had been focused only on XRD based analysis, a clear understanding of the molecular structure and how this was important to the issues at hand was not yet developed. More importantly, the use of the proper detection mode (ATR vs. Transmission) for the type of material analysis at hand allowed our work to be able to extract the maximum amount of vibrational structure to be analyzed. This, along with other structural information (such as crystallographic data) was especially important when it came down to identifying possible groups ( $\mathrm{HAsO}_{4}$ vs. $\mathrm{AsO}_{4}$ ) that could occur in the phase of interest which allowed us to correct previous formulae. Once the proper method of analysis was employed, the positive identification of these phases could be properly established (along with the corresponding elemental and structural data) and the identification of new phases by previous studies was eliminated.

Moreover, the use of vibrational spectroscopy gave us insight into the changes in the molecular solid-solution symmetry that occurs in the structure of a crystallographically unknown phase (BFAS), something that would be useful later when the crystal structure of this phase was solved via high resolution synchrotron diffraction data. The use of vibrational spectroscopy of industrially crystalline and non crystalline products gave us the advantage of tuning into the molecules of interest $\left(\mathrm{AsO}_{4}\right)$ and also offered the much lower detection limits then complementary XRD methods (4-5 w.t \%) needed to analyze these samples. A nice correlation between the arsenate vibrational structure of the industrial sample and that of our synthetically produced phases was achieved but it should be noted that this information is only qualitative and $100 \%$ identification of the nature of the arsenic species in these samples is not possible using vibrational spectroscopy, XRD, or XAS based methods. This latter result arises from the fact that in the case of industrial samples where more than one, two, three arsenate phase maybe present \{some which may have the same or more than one type of local arsenic coordination to the $3^{\text {rd }}$ shell, e.g. yukonite-arseniosiderite\}, the positive contribution to the arsenate signal from all the phases (in various coordination's and symmetries) becomes nearly impossible to qualitatively or quantitatively (via fitting or modelling) identify as a result of the fact that the contribution from each phase to the overall signal and features is almost impossible to replicate. This is especially true at low concentrations and in the presence of a multicomponent matrix which can also have additional effects to the signal observed. Moreover, limitations of vibrational spectroscopy were observed in cases where phases such 
as hematite and elemental sulfur (which have large Raman cross sections) were abundant in industrial products. There Raman spectroscopy was only able to detect one of these phases in spite of the fact that the other was well in abundance of the Raman detection limit. This further shows the reader, the complexity that a multicomponent sample has on the vibrational structure expressed in the current spectroscopic techniques.

Finally, for the $\mathrm{N} 19-\mathrm{TiO}_{2}$ biding mechanism, discrepancies in the coordination information inferred based on the $\Delta \mathrm{v}$ method for the same system led us to further evaluate the detailed vibrational structure of the system. In this case, the combination of the spectroscopic information coupled with the aid of the imaging data allowed us to determine how the molecular groups of interest on the TiO2 substrates and N719 molecule behaved during the binding event, but also how these were distributed among the two $\mathrm{TiO}_{2}$ substrates investigated. Using the information of previous works along with the new gathered data from our studies, the evolution of a new binding mechanism which involved a bridged covalent bonded-H-bonding type of mechanism was developed for this system. The main draw back or limitation of the use of vibrational spectroscopy in this study was the fact that the imaging of the substrates was limited to micro-scale analysis as a result of the laser beam used; however, it is well known for these systems that the internal surfaces are uniformly covered by a monolayer of dye, and a such the use of nano-imaging techniques such as AFM-Raman analysis may give more insight into how these groups are distributed among the various substrates at the nano-level but also probe the changes of the molecular groups of interest at the nano-scale in which bulk like effects may be avoided.

In this chapter, three distinct case studies were presented to the reader where the use and application of vibrational spectroscopy in correlation with other analytical data was employed to give new insights into the various problems at hand. Most importantly, the limitations of the techniques (vibrational, XRD, XAS) employed in previous studies and in our work was presented to show how these restrictions may be overcome by the combination of various techniques, detection methods and a good knowledge of the systems theory at hand. However, the reader is forewarned to be cautious when using vibrational spectroscopy (XAS or XRD) to identify multiple phases in a complex matrix; often specialist in these techniques or research facilities (e.g. synchrotron facilities) offer that each one of these can offer a solution to identify all of the main phase of interest found in a complex sample but this is often not true and is beyond the technological (and theoretical) capabilities of these techniques and facilities. A perfect way to test such a concept is to test a known multiphase $(>4)$ poorly crystalline industrial or natural sample and see if indeed any of these techniques (vibrational, X-ray Absorption Spectroscopy or X-ray Diffraction) identify all the phases in the sample, naturally they will not for now.

\section{Acknowledgments}

The authors would like to thank several instrumental people

from various universities and research facilities who were co-authors of these published works or gave their time, funding and efforts to these studies: Prof. George P.Demopoulos and Dr. Jeff N. Cutler Dr. Samir Elouatik, Dr. Hassane Assoudi, Dr. Leventer Becze, Dr. Gerry Ventruti, Petr Fiurasek, Xu Dong Li, Mert Celikin,Tom Regier, Dr. R. I. R. Blyth, Dr. Yonfeng $\mathrm{Hu}$. We also like to thank Joan Kaylor from the Redpath Museum at McGill University for the donation of the Romanech Arseniosiderite sample and Dr. Richard Herd, Curator of the National Collections of Canada for the donation of the original natural Tagish 
Lake Yukonite sample. Research described in this book chapter for the X-ray Absorption Analysis was performed at the Canadian Light Source which is acknowledged.

\section{References}

Bastians, S.; Crump, G.; Griffith, W. P.; Withnall, R. (2004) Raspite and studtite: Raman spectra of two unique minerals. J. Raman Spectrosc. Vol. 35, No. 8-9, (January 2004), pp. 726-731, ISSN: 0377-0486.

Bazzan, G.; Deneault, J. R.; Kang, T.K.; Taylor, B.E.; Durstock, M.F. (2011) Nanoparticle/Dye Interface Optimization in Dye-Sensitized Solar Cells. Adv. Funct. Mater. Vol. 21, No. 17, (Septemeber 2011), pp. 3268-3274, ISSN: 1616-3028.

Becze, L.; Gomez, M. A.; Petkov, V.; Cutler, J. N.; Demopoulos, G. P. (2010) The Potential Arsenic Role of Ca-Fe(III)-AsO4 Compounds in Lime Neutralized Co-Precipitation Tailings, Proceedings of Uranium 2010 and 40th Annual Hydrometallurgy Meeting, Uranium Processing, Vol. II, pp. 327-336, Saskatoon, SK, Canada, August 2010.

Becze, L.; Demopoulos, G. P. (2007) Synthesis and Stability Evaluation of Ca-Fe(III)-AsO 4 Phases, Extraction and Processing Proceedings, B. Davis and M. Free, Eds., TMS, pp. 11-17, ISBN: 978-0-470-93163-9.

Becze, L.; Gomez, M. A.; Le Berre, J. F.; Pierre, B.; Demopoulos, G. P. (2009) Formation of Massive Gunningite-Jarosite Scale in an Industrial Zinc Pressure Leach Autoclave: a Characterization Study. Can. Metall. Q. Vol. 48, No. 2, (June 2009), pp. 99-108, ISSN: 0008-4433.

Berezowsky, R.; Xue, T.; Collins, M.; Makwana, M.; Barton-Jones, I.; Southgate, M.; Maclean, J. (1999) Pressure leaching las cruces copper ore, JOM, Vol. 51, No. 12, (December 1999), pp. 36-40, ISSN: 1047-4838.

Bruce, R.; Mayhew, K.; Mean, R.; Kadereit, H.; Nagy A.; Wagner, O. (2011) Unlocking Value in Copper Arsenic Sulphide Resources with Copper-Arsenic CESL Technology, Hydro-copper Conference Proceeding. Viña del Mar, Chile, July 2011

Burns, P.C.; Hughes, K. A. (2003) Studtite, $\left[\left(\mathrm{UO}_{2}\right)\left(\mathrm{O}_{2}\right)\left(\mathrm{H}_{2} \mathrm{O}\right)_{2}\right]\left(\mathrm{H}_{2} \mathrm{O}\right)_{2}$ : The first structure of a peroxide mineral. Am. Mineral. Vol. 88, No. 7, (July 2003), pp. 1165-1168, ISSN: 1945-3027.

Charbonneau, C.; Lee, K. E.; Shan, G. B.; Gomez, M. A.; Gauvin, R.; Demopoulos, G. P. (2010) Preparation and DSSC performance of mesoporous film photoanodes based on hydroxyl-rich anatase nanocrystallites. Electrochem. Solid-State Lett., Vol. 13, No. 8, (May 2010 ), pp. H257-H260, ISSN: 1944-8775.

Coates, J. (1998) Vibrational Spectroscopy: Instrumentation for Infrared and Raman Spectroscopy. Appl. Spectrosc. Rev. Vol. 33, No. 4, (August 2006), pp. 267-425, ISSN: 1520-569X.

Dana, J. D.; Dana, E. S.; Palache, C.; Berman, H.; Frondel, C. (1976) The System of Mineralogy of Dana, Seventh ed., Vol. 2, John Wiley and Sons, Inc., ISBN: 0471193100, New York, pp. 955-956.

Deacon, G. B.; Phillips, R. J. (1980) Relationships between the carbon-oxygen stretching frequencies of carboxylato complexes and the type of carboxylate coordination. Coord. Chem. Rev. Vol. 33, No. 3, (October 1980), pp. 227-250, ISSN: 0010-8545.

De Angelis, F.; Fantacci, S.; Selloni, A.; Nazeeruddin, Md. K.; Gratzel, M. (2007a) TimeDependent Density Functional Theory Investigations on the Excited States of 
$\mathrm{Ru}(\mathrm{II})$-Dye-Sensitized $\mathrm{TiO}_{2}$ Nanoparticles: The Role of Sensitizer Protonation. J. Am. Chem. Soc. Vol. 129, No. 46, (October 2007), pp. 14156-14157, ISSN: 0002-7863.

De Angelis, F.; Fantacci, S.; Selloni, A.; Gratzel., M.; Nazeeruddine, Md. K. (2007b) Influence of the Sensitizer Adsorption Mode on the Open-Circuit Potential of Dye-Sensitized Solar Cells. Nano Lett. Vol. 7, No. 10, (September 2007), pp. 3189-3195. ISSN: 15306992.

Defreyne, J.; Cabra, T. (2009) Early copper production results from Vale's hydrometallurgical CESL refinery, ALTA Conference Proceedings, Perth, Australia, May 2009.

de Groot, F. M. F.; Fuggle, J. C.; Thole, B. T.; Sawatzky, G. A. (1990) 2p x-ray absorption of $2 \mathrm{~d}$ transition-metal compounds: An atomic multiplet description including the crystal field. Phys. Rev. B: Condens. Matter, Vol. 42, No. 9, (September 1990), pp. 5459-5468, ISSN: 1550-235X.

de Groot F. M. F. (2005) Multiplet effects in X-ray spectroscopy. Coord. Chem. Rev. Vol. 249, No. 1-2, (January 2005), pp. 31-63, ISSN: 0010-8545.

Demopoulos, G. P.; Charbonneau, C.; Lee, K. E.; Shan, G. B.; Gomez, M. A.; Gauvin, R. (2009) Synthesis of Hydroxyl-Rich Anatase Nanocrystallites, Their Characterization and Performance as Photoanode in Dye-Sensitized Solar Cells. ECS Trans. Vol. 21, No. 1, (July 2009), pp. 23-34, ISSN: 1938-6737.

Drahota, P.; Rohovec, J.; Filippi, M.; Mihaljevic, M.; Rychlovsky, P.; Cerveny, V.; Pertold, Z. (2009) Mineralogical and geochemical controls of arsenic speciation and mobility under different redox conditions in soli, sediment and water at the Mokrsko-West gold deposit, Czech Republic. Sci. Total. Environ. Vol. 407, No. 10, (May 2009), pp. 3372- 3384, ISSN: 0048-9697.

Drahota, P.; Filippi, M. (2009) Secondary arsenic minerals in the environment: A review. Environ. Int. Vol. 35, No. 8, (November 2009), pp. 1243-1255, ISSN: 0160-4120.

Dunn, P. J. (1982) New data for pitticite and a second occurrence of yukonite at Sterling Hill, New Jersey. Mineral. Mag. Vol. 46, pp. 261-264, ISSN: 0026-461X.

Dutrizac, J. E.; Jambor, J. L. (2007) Characterization of the iron arsenate-sulfate compounds precipitated at elevated temperatures. Hydrometallurgy. Vol. 86, No. 3-4, (May 2007), pp. 147-163, ISSN: 0304-386X.

Dymov, I.; Ferron, C. J.; Phillips, W. (2004) Pilot Plant Evaluation of a Hybrid Biological Leaching-Pressure Oxidation Process for Auriferous Arsenopyrite/Pyrite Feedstocks. In Pressure Hydrometallurgy (eds. Collins M. J. and Papangelakis V.G.). CIM, pp. 735-750, Banff, Canada, October 2004.

Falaras, P. (1998) Synergetic effect of carboxylic acid functional groups and fractal surface characteristics for efficient dye sensitization of titanium oxide. Sol. Energy Mater. Sol. Cells. Vol. 53, No. 1-2, (May 1998), pp. 163-175, ISSN: 0927-0248.

Fernández-Martínez, A.; Cuello, G. J.; Johnson, M. R.; Bardelli, F.; Román-Ross, G.; Charlet, L.; Turrillas, X. (2008) Arsenate Incorporation in Gypsum Probed by Neutron, Xray Scattering and Density Functional Theory Modeling. J. Phys. Chem. A, Vol. 112, No. 23, (May 2008), pp. 5159-5166, ISSN: 1089-5639.

Filippi, M.; Golias, V.; Pertold, Z. (2004) Arsenic in contaminated soils and anthropogenic deposits at the Mokrsko, Roudny, and Kasperske Hory gold deposits. Environ. Geol. Vol. 45, No. 5, (March 2004), pp. 716-730, ISSN: 1432-0495. 
Filippi, M.; Dousova, B.; Machovic, V. (2007) Mineralogical speciation of arsenic in soils above the Mokrsko-west gold deposits, Czech Republic. Geoderma. Vol. 139, No. 12, (April 2007), pp. 154-170, ISSN: 0016-7061.

Fillipou, D.; Demopoulos, G. P. (1997) Arsenic Immobilization by Controlled Scorodite Precipitation. JOM. Vol. 49, No. 12, (December 1997), pp. 52-55, ISSN: 1047-4838.

Finnie, K. S.; Bartlett, J. R.; Woolfrey, J. L. (1998) Vibrational Spectroscopic Study of the Coordination of (2,2'-Bipyridyl-4,4'-dicarboxylic acid)ruthenium(II) Complexes to the Surface of Nanocrystalline Titania. Langmuir. Vol. 14, No. 10, (February 1998), pp. 2744-2849, ISSN: 0743-7463.

Fleet, M. E.; Liu, X. (2009) Calcium L2,3-edge XANES of carbonates, carbonate apatite and oldhamite (CaS). Am. Mineral. Vol. 94, No. 8-9, (August-September 2009), pp. 12351241, ISSN: 1945-3027.

Foshac, W. F. (1937) Carminite and associated minerals from Mapimi, Mexico. Am. Mineral. Vol. 22, No. 5, (May 1937), pp. 479-484, ISSN: 1945-3027.

Frost, R.; Weier, M.; Martens, W. (2006) Raman microscopy of synthetic goudeyite $\left(\mathrm{YCu}_{6}\left(\mathrm{AsO}_{4}\right)_{2}(\mathrm{OH})_{6} 3 \mathrm{H}_{2} \mathrm{O}\right)$. Spectrochim. Acta A. Vol. 63, No. 3, (March 2006), pp. 685-689, ISSN: 1386-1425.

Fujita, T.; Taguchi, R.; Abumiya, M.; Matsumoto, M.; Shibata, E.; Nakamura, T. (2008) Novel atmospheric scorodite synthesis by oxidation of ferrous sulfate solution. Part I Hydrometallurgy, Vol. 90, No. 2-4, (February 2008), pp. 92-102, ISSN: 0304-386X.

Garavelli, A.; Pinto, D.; Vurro, F.; Mellini, M.; Viti, C.; Balic-Zuni, T.; Della Ventura, G. (2009) Yukonite from the Grotta della Monaca Cave, Sant'Agata Di Esaro, Italy: Characterization and comparison with Cotype material from the Daulton ine, Yukon, Canada. Can. Mineral. Vol. 47, No. 1, (February 2009), pp. 39-51, ISSN: 00084476.

Gomez, M. A.; Becze, L.; Blyth, R. I. R.; Cutler, J. N.; Demopoulos, G. P. (2010a) Molecular and structural investigation of yukonite (synthetic \& natural) and its relation to arseniosiderite. Geochim. Cosmochim. Acta. Vol 74, No. 20, (October 2010), pp. 58355851, ISSN: 0016-7037.

Gomez, M. A.; Assaaoudi, H.; Becze, L.; Cutler, J. N.; Demopoulos, G. P. (2010b) Vibrational spectroscopy study of hydrothermally produced scorodite $\left(\mathrm{FeAsO}_{4} \cdot 2 \mathrm{H}_{2} \mathrm{O}\right)$, ferric arsenate sub-hydrate $\left(\mathrm{FAsH} ; \mathrm{FeAsO}_{4} \cdot 0.75 \mathrm{H}_{2} \mathrm{O}\right)$ and basic ferric arsenate sulphate (BFAS; $\left.\mathrm{Fe}\left[\left(\mathrm{AsO}_{4}\right)_{1-\mathrm{x}}\left(\mathrm{SO}_{4}\right)_{\mathrm{x}}(\mathrm{OH})_{\mathrm{x}}\right] \mathrm{wH}_{2} \mathrm{O}\right)$ J. Raman Spectrosc. Vol. 41, No.2, (February 2010), pp. 212-221, ISSN: 0377-0486.

Gomez, M. A.; Becze, L.; Cutler, J. N.; Demopoulos, G. P. (2011a) On the hydrothermal reaction chemistry and characterization of ferric arsenate phases precipitated from $\mathrm{Fe}_{2}\left(\mathrm{SO}_{4}\right)_{3}-\mathrm{As}_{2} \mathrm{O}_{5}-\mathrm{H}_{2} \mathrm{SO}_{4}$ solutions. Hydrometallurgy. Vol. 107, No. 3-4, (May 2011), pp. 74-90, ISSN: 0304-386X.

Gomez, M. A.; Le Berre, J. F.; Assaaoudi, H.; Demopoulos, G. P. (2011b) Raman spectroscopic study of the hydrogen and arsenate bonding environment in isostructural synthetic arsenates of the variscite group- $\mathrm{M}^{3+} \mathrm{AsO}_{4} \cdot 2 \mathrm{H}_{2} \mathrm{O}\left(\mathrm{M}^{3+}=\mathrm{Fe}\right.$, Al. In and Ga)-implications for arsenic release in water. J. Raman Spectrosc. Vol. 42, No. 1, (January 2011), pp. 62-71, ISSN: 0377-0486.

Gomez, M. A.; Becze, L.; Celikin, M.; Demopoulos, G. P. (2011c) The effect of copper on the precipitation of scorodite $\left(\mathrm{FeAsO}_{4} \cdot 2 \mathrm{H}_{2} \mathrm{O}\right)$ under hydrothermal conditions: Evidence 
for a hydrated copper containing ferric arsenate sulfate-short lived intermediate. J. Colloid Interface Sci. Vol. 360, No. 2, (August 2011), pp. 508-518, ISSN: 0021-9797.

Gomez, M. A.; Ventruti, G.; Assaaoudi, H.; Ceklin, M.; Putz, H; Lee, K. E.; Demopoulos, G. P. (2011d) The nature of synthetic Basic Ferric Sulfate and Basic Ferric Arsenate Sulfate: A crystal and molecular structure determination and applications of their materials properties. (Submitted)

Gratzel, M. (2001) Photoelectrochemical cells. Nature. Vol. 414, (November 2001), pp. 338344, ISSN: 0028-0836.

Guana, X.; Wang, J.; Chusue. C. C. (2008) Removal of arsenic from water using granular ferric hydroxide: Macroscopic and microscopic studies. J. Hazard. Mater. Vol. 156, No. 1-3, (August 2008), pp. 178-185, ISSN: 0304-3894.

Hagfeldt, A.; Boschloo, G.; Sun, L.; Kloo, L.; Pettersson, H. (2010) Dye-sensitized Solar Cells. Chem. Rev. Vol. 110, No. 10, (September 2010), pp. 6595-6663, ISSN: 0009-2665.

Harris, D. C.; Bertolucci, M. D. (1989) Symmetry and Spectroscopy: An Introduction to Vibrational and Electronic Spectroscopy. Dove Publications, Inc., ISBN: 048666144X, New York.

Hawthorne, F. C. (1976) The Hydrogen Positions in Scorodite. Acta Crystallogr. Sect. B: Struct. Sci. Vol. 32, No.10, (October 1976), pp. 2891-92, ISSN: 0108-7681.

Hirose, F.; Kuribayashi, K.; Suzuki, T.; Narita, Y.; Kimura, Y.; Niwano, M. (2008) UV Treatment Effect on $\mathrm{TiO}_{2}$ Electrodes in Dye-Sensitized Solar Cells with N719 Sensitizer Investigated by Infrared Absorption Spectroscopy. Electrochem. SolidState Lett. Vol. 11, No. 12, (October 2009), pp. A109-A111, ISSN: 1944-8775.

Hollas, J. M. (2004) Modern Spectroscopy. (6th edn), Wiley, ISBN: 0470844167, New York.

Jakeman, R. J. B.; Kwiecien, M. J.; Reiff, W. M.; Cheetham, K.; Torardi, C. C. (1991) A new ferric orthoarsenate hydrate: structure and magnetic ordering of $\mathrm{FeAsO}_{4} \cdot 3 / 4 \mathrm{H}_{2} \mathrm{O}$. Inorg. Chem. Vol. 30, No. 13, (June 1991), pp. 2806-2811, ISSN: 0020-1669.

Jambor, J. L. (1966) Abstract of paper presented at the eleventh meeting: Re-examination of yukonite. Can. Mineral. Vol. 8, pp. 667-668, ISSN: 0008-4476.

Jia, Y.; Demopoulos, G. P. (2005) Adsorption of Arsenate onto Ferrihydrite from Aqueous Solution: Influence of Media (Sulphate vs Nitrate), Added Gypsum, and $\mathrm{pH}$ Alteration. Enviro. Sci.Technol. Vol. 39, Vol. 24, (November 2005), 9523-9527. ISSN: 0013-936X.

Jia, Y.; Demopoulos, G. P. (2007) Coprecipitation of arsenate with iron(III) in aqueous sulfate media: effect of time, lime as base and co-ions on arsenic retention. Water Res. Vol. 42, No. 3, (August 2007) pp. 661-6688. ISSN: 0043-1354.

Kay, A.; Gratzel, M. (2002) Dye-Sensitized Core-Shell Nanocrystals: Improved Efficiency of Mesoporous Tin Oxide Electrodes Coated with a Thin Layer of an Insulating Oxide. Chem. Mater. Vol. 14, No. 7, (June 2002), pp. 2930-2935, ISSN: 0897-4756.

Koenig, G. A. (1889) VI. Neue amerikanische Mineralvorkommen.1. Mazapilit. Z. Kristallogr. Vol. 17, pp. 85-88, ISSN: 0044-2968.

Krause, E.; Ettel, V. A. (1989) Solubilities and stabilities of ferric arsenate compounds. Hydrometallurgy. Vol. 22, No. 3, (August 1989), pp. 311-337, ISSN: 0304-386X.

Kroon, J. M.; Bakker, N. J.; Smit, H. J. P.; Liska, P.; Thampi, K. R.; Wang, P.; Zakeeruddin, S. M.; Gratzel, M.; Hinsch, A.; Hore, S.; Wurfel, U.; Sastrawan, R.; Durrant, J. R.; Palomares, E.; Pettersson, H.; Gruszecki, T.; Walter, J.; Skupien, K.; Tulloc, G. E. 
(2007) Nanocrystalline dye-sensitized solar cells having maximum performance. Prog. Photovolt: Res. Appl. Vol. 15, No. 1, (January 2007), pp. 1-18, ISSN: 1099-159X.

Langmuir, D.; Mahoney, J.; MacDonald, A.; Rowson, J. (1999) Predicting arsenic concentrations in the pore waters of buried uranium mill tailings. Geochim. Cosmochim. Acta. Vol. 63, No. 19-20, (October 1999), pp. 3379-3394, ISSN: 0016-7037.

Langmuir, D.; Mahoney, J.; Rowson, J. (2006) Solubility products of amorphous ferric arsenate and crystalline Scorodite $\left(\mathrm{FeAsO}_{4} \cdot 2 \mathrm{H}_{2} \mathrm{O}\right)$ and their application to arsenic behavior in buried mine tailings. Geochim. Cosmochim. Acta. Vol. 70, No. 12, (June 2006), pp. 2942-2956, ISSN: 0016-7037.

Larsen, E. S. III (1940) Overite and montgomeryite: two new minerals from Fairfield, Utah. Am. Mineral. Vol. 25, No. 5, (May 1940), pp. 315-326, ISSN: 1945-3027.

Lee, K. E.; Gomez, M. A.; Elouatik, S.; Demopoulos, G. P. (2010) Further understanding of the adsorption of N719 complex on Anatase $\mathrm{TiO}_{2}$ films for DSSC applications using Vibrational spectroscopy and Confocal Raman imaging. Langmuir, Vol. 26, No. 12, (March 2010), pp. 9575-9583, ISSN: 0743-7463.

Lee, K. E.; Gomez, M. A.; Regier, T.; Hu, Y.; Demopoulos, G. P. (2011a) Electronic Studies of $\mathrm{N} 719 / \mathrm{TiO}_{2}$ interface for DSSC applications: A combined XAS and XPS study. $J$. Phys. Chem. C. Vol. 115, No. 13, (March 2011), pp. 5692-5707, ISSN: 1932-7447.

Lee, K. E.; Gomez, M. A.; Shan, G. B.; Demopoulos, G. P. (2011b) Vibrational Spectroscopic Imaging of $\mathrm{N} 19-\mathrm{TiO}_{2}$ Films in the High Wavenumber Region Coupled to Electrical Impedance Spectroscopy. J. Electrochem. Soc., Vol. 158, No. 7, (May 2011), pp. 1-7, ISSN: 0013-4651.

Leon, C. P.; Kador, L.; Peng, B.; Thelakkat, M. (2006) Characterization of the Adsorption of Ru-bpy Dyes on Mesoporous $\mathrm{TiO}_{2}$ Films with UV-Vis, Raman, and FTIR Spectroscopies. J. Phys. Chem. B. Vol. No. 17, (October 2005), 110, pp. 8723-8730, ISSN: $1089-5647$.

Libowitsky, E. (1999) Correlation of $\mathrm{O}-\mathrm{H}$ stretching frequencies and $\mathrm{OH} \bullet \bullet \bullet \mathrm{O}$ hydrogen bond lengths in minerals. Monatsh. Chem. Vol. 130, No. 8, (August 1999), pp. 10471059, ISSN: 1434-4475.

Mayhew, K.; Parhar, P.; Salomon-de-Friedberg, H. (2010) CESL Process as Applied to Enargite-Rich Copper Concentrates. Proceedings of the 7th International Copper-Cobre Conference, Vol. 5, pp. 1983-1998, Hamburg, Germany, June 2010.

Moore, P. A.; Ito, J. (1974) I. Jahnsite, segelerite, and robertsite, three new transition metal phosphate species. II. Redefinition of overite, an isotype of segelerite. III. Isotypy of robertsite, mitridatite, and arseniosiderite . Am. Mineral. Vol. 59, No. 1-2, (January February 1974), pp. 48-59, ISSN: 1945-3027.

Moore, P. A.; Araki, T. (1977a) Mitridatite, $\mathrm{Ca}_{6}\left(\mathrm{H}_{2} \mathrm{O}\right)_{6}\left[\mathrm{Fe}^{\mathrm{III}} \mathrm{O}_{6}\left(\mathrm{PO}_{4}\right)_{9}\right] \cdot 3 \mathrm{H}_{2} \mathrm{O}$. A noteworthy octahedral sheet structure. Inorg. Chem. Vol. 16, No. 5, (May 1977), pp. 1096-1106, ISSN: 0020-1669.

Moore, P. A.; Araki, T. (1977b) Mitridatite: a remarkable octahedral sheet structure. Mineral. Mag. Vol. 41, (December 1977), pp. 527-528, ISSN: 0026-461X.

Murakoshi, K.; Kano, G.; Wada, Y.; Yanagida, S.; Miyazaki, H.; Matsumoto, M.; Murasawa, S. (1995) Importance of binding states between photosensitizing molecules and the $\mathrm{TiO}_{2}$ surface for efficiency in a dye-sensitized solar cell. J. Electroanal. Chem. Vol. 396, No. 1-2, (October 1995), pp. 27-34, ISSN: 1945-7111. 
Myneni, S. C. B.; Traina, S. J.; Waychunas, G. A.; Logan, T. J. (1998) Experimental and theoretical vibrational spectroscopic evaluation of arsenate coordination in aqueous solutions, solids, and at mineral-water interfaces. Geochim. Cosmochim. Acta. Vol. 62, No. 19-20, (October 1998), pp. 3285-3661, ISSN: 0016-7037.

Nakamoto, K. (2009) Infrared and Raman Spectra of Inorganic and Coordination Compounds. Part A: Theory and Applications in Inorganic Chemistry (6th edn), Wiley, ISBN: 0471163929, New York.

Nazeeruddin, Md. K.; Humpry-Baker, R.; Liska, P.; Gratzel, M. (2003) Investigation of Sensitizer Adsorption and the Influence of Protons on Current and Voltage of a Dye-Sensitized Nanocrystalline $\mathrm{TiO}_{2}$ Solar Cell. J. Phys. Chem. B. Vol. 107, No. 34, (March 2003), pp. 8981-8987, ISSN: 1089-5647.

Nishikawa, O.; Okrugin, V.; Belkova, N.; Saji, I.; Shiraki, K.; Tazaki, K. (2006) Crystal symmetry and chemical composition of yukonite: TEM study of specimens collected from Nalychevskie hot springs, Kamchatka, Russia and from Venus mine, Yukon Territory, Canada. Mineral. Mag. Vol. 70, No. 1, (February 2006), pp. 73-81, ISSN: 0026-461X.

Paktunc, D.; Foster, A.; Laflamme, G. (2003) Speciation and characterization of arsenic in Ketza river mine tailings using X-ray absorption spectroscopy. Environ. Sci. Techn. Vol. 37, No., (10), (May 2003), pp. 2067-2074, ISSN: 0013-936X.

Paktunc, D.; Foster, A.; Heald, S.; Laflamme, G. (2004) Speciation and characterization of arsenic in gold ores and cyanidation tailings using X-ray absorption spectroscopy. Geochim. Cosmochim. Acta. Vol. 68, No. 5, (March 2004), pp. 969-983, ISSN: 00167037.

Peter, L. M. (2011) The Gratzel Cell: Where Next? J. Phys. Chem. Lett., Vol. 2, No. 15, (July 2011), pp 1861-1867, ISSN: 1948-7185.

Pieczka, A.; Golobiowska, B.; Franus, W. (1998) Yukonite, a rare Ca-Fe arsenate, from Redziny (Sudetes, Poland). Eur. J. Mineral. Vol. 10, No. 6, (July 1998), pp. 1367-1370, ISSN: 0935-1221.

Riveros, P. A.; Dutrizac, J. E.; Spencer, P. (2001) Arsenic Disposal Practices in the Metallurgical Industry. Can. Metall. Q. Vol. 40, No. 4, pp. 395-420, ISSN: 0008-4433.

Ross, D. R.; Post, J. E. (1997) New data on yukonite. Powder Diffr. Vol. 12, pp. 113-116, ISSN: 0885-7156.

Schwendtner, K.; Kolitsch, U. (2007) Eur. J. Mineral. Vol. 19, No. 3, (May-June 2007), pp. 399_ 409, ISSN: 0935-1221.

Scrosati, B.; Garche, J. (2010) Lithium batteries: Status, prospects and future. J. Power Sources. Vol. 195, No. 9, (May 2010), pp. 2419-2430, ISSN: 0378-7753.

Shklover, V.; Ovchinnikov, Y. E.; Braginsky, L. S.; Zakeeruddine, S. M.; Gratzel, M. (1998) Structure of Organic/Inorganic Interface in Assembled Materials Comprising Molecular Components. Crystal Structure of the Sensitizer Bis $\left[\left(4,4^{\prime}\right.\right.$-carboxy-2,2'bipyridine)(thiocyanato)]ruthenium(II). Chem. Mater. Vol. 10, No. 9, (July 1998), pp. 2533-2541, ISSN: 0897-4756.

Singhania, S.; Wang, Q.; Filippou, D.; Demopoulos, G. P. (2005) Temperature and seeding effects on the precipitation of scorodite from sulfate solutions under atmosphericpressure conditions. Metall. Mater. Trans. B. Vol. 36, No. 3, (June 2005), pp. 327-333, ISSN: 1543-1916. 
Srinivas, K.; Yesudas, K.; Bhanuprakash, K.; Rao, V. J.; Girbabu, L. (2009) A Combined Experimental and Computational Investigation of Anthracene Based Sensitizers for DSSC: Comparison of Cyanoacrylic and Malonic Acid Electron Withdrawing Groups Binding onto the $\mathrm{TiO}_{2}$ Anatase (101) Surface. J. Phys. Chem. C. Vol. 113, No. 46, (October 2009), pp. 20117-20126, ISSN: 1932-7447.

Swash, P. M.; Monhemius; A. J. (1994) Hydrothermal precipitation from aqueous solutions containing iron (III), arsenate and sulfate, In Hydrometallurgy '94, ISBN 978-0-41259780-0, Cambridge, England, July 1994.

Swash, P. M. (1996) The hydrothermal precipitation of Arsenic solids in the Ca-Fe- $\mathrm{AsO}_{4}-\mathrm{SO}_{4}$ system at elevated temperature, Ph.D. Dissertation, Imperial College of Science, Technology and Medicine, University of London, London.

Taratula, O.; Rochford, J.; Piotrowiak, P.; Galoppini, E. (2006) Pyrene-Terminated Phenylenethynylene Rigid Linkers Anchored to Metal Oxide Nanoparticles. J. Phys. Chem. B. Vol. 110, No. 32, (July 2006), pp. 15734-15741, ISSN: 1089-5647.

Tyrrell, J. B.; Graham, R. P. D. (1913) Yukonite, a new hydrous arsenate of iron and calcium, from Tagish Lake, Yukon Territory, Canada; with a note on the Associated Symplesite. Trans. R. Soc. Can., section. IV. pp. 13-18, ISSN: 0035-9122.

Ugarte, F. J. G.; Monhemius, A. J. (1992) Characterization of high temperature arsenic containing residues from hydrometallurgical processes. Hydrometallurgy. Vol. 30, No. 1-3, (June 1992), pp. 69-86, ISSN: 0304-386X.

Walker, S. R.; Jamieson, H. E.; Lanzirotti, A.; Andrade, C. F.; Hall, G. E. M. (2005) The speciation of arsenic in iron oxides in mine wastes from the giant gold mine, N.W.T.: application of synchrotron micro-XRD and micro-XANES at the grain scale. Can. Mineral. Vol. 43, No. 4, (August 2005), pp. 1205-1224, ISSN: 0008-4476.

Walker, S. R.; Parsons, M. B.; Jamieson, H. E.; Lanzirotti, A. (2009) Arsenic mineralogy of near-surface tailings and soils: Influences on arsenic mobility and bioaccessibility in the Nova Scotia gold mining districts. Can. Mineral. Vol. 47, No. 3, (June 2009), pp. 533-556, ISSN: 0008-4476.

Wang, W.; Lin, Z. (2010) Dye-Sensitized $\mathrm{TiO}_{2}$ Nanotube Solar Cells with Markedly Enhanced Performance via Rational Surface Engineering. Chem. Mater. Vol. 22, No. 2, (December 2009), pp. 579-584, ISSN: 0897-4756. 


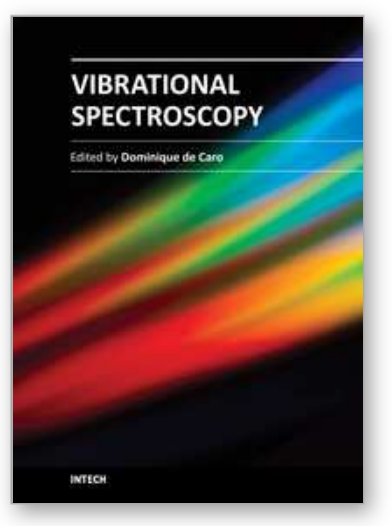

\author{
Vibrational Spectroscopy \\ Edited by Prof. Dominique De Caro
}

ISBN 978-953-51-0107-9

Hard cover, 168 pages

Publisher InTech

Published online 24, February, 2012

Published in print edition February, 2012

The infrared and Raman spectroscopy have applications in numerous fields, namely chemistry, physics, astronomy, biology, medicine, geology, mineralogy etc. This book provides some examples of the use of vibrational spectroscopy in supramolecular chemistry, inorganic chemistry, solid state physics, but also in the fields of molecule-based materials or organic-inorganic interfaces.

\title{
How to reference
}

In order to correctly reference this scholarly work, feel free to copy and paste the following:

Mario Alberto Gómez and Kee eun Lee (2012). Vibrational Spectroscopy of Complex Synthetic and Industrial Products, Vibrational Spectroscopy, Prof. Dominique De Caro (Ed.), ISBN: 978-953-51-0107-9, InTech, Available from: http://www.intechopen.com/books/vibrational-spectroscopy/vibrational-spectroscopy-ofcomplex-synthetic-and-industrial-products-

\section{INTECH}

open science | open minds

\author{
InTech Europe \\ University Campus STeP Ri \\ Slavka Krautzeka 83/A \\ 51000 Rijeka, Croatia \\ Phone: +385 (51) 770447 \\ Fax: +385 (51) 686166 \\ www.intechopen.com
}

\author{
InTech China \\ Unit 405, Office Block, Hotel Equatorial Shanghai \\ No.65, Yan An Road (West), Shanghai, 200040, China \\ 中国上海市延安西路65号上海国际贵都大饭店办公楼 405 单元 \\ Phone: +86-21-62489820 \\ Fax: +86-21-62489821
}


(C) 2012 The Author(s). Licensee IntechOpen. This is an open access article distributed under the terms of the Creative Commons Attribution 3.0 License, which permits unrestricted use, distribution, and reproduction in any medium, provided the original work is properly cited. 